\section{Review Article}

Clinical Chemistry

Ann Lab Med 2022;42:3-23

https://doi.org/10.3343/alm.2022.42.1.3

ISSN 2234-3806 elSSN 2234-3814
ANNALS OF

LABORATORY

MEDICINE

\title{
Hormone Immunoassay Interference: A 2021 Update
}

\author{
Khaldoun Ghazal (), Pharm., Ph.D., Severine Brabant 도, M.D., Dominique Prie iㅜ, M.D., Ph.D., \\ and Marie-Liesse Piketty $\mathbb{1}$, Pharm., Ph.D. \\ Assistance Publique Hopitaux de Paris, Department of Functional Explorations, Necker Enfants Malades Hospital, Paris-Centre University, Paris Cedex, \\ France
}

Immunoassays are powerful qualitative and quantitative analytical techniques. Since the first description of an immunoassay method in 1959, advances have been made in assay designs and analytical characteristics, opening the door for their widespread implementation in clinical laboratories. Clinical endocrinology is closely linked to laboratory medicine because hormone quantification is important for the diagnosis, treatment, and prognosis of endocrine disorders. Several interferences in immunoassays have been identified through the years; although some are no longer encountered in daily practice, cross-reaction, heterophile antibodies, biotin, and anti-analyte antibodies still cause problems. Newer interferences are also emerging with the development of new therapies. The interfering substance may be exogenous (e.g., a drug or substance absorbed by the patient) or endogenous (e.g., antibodies produced by the patient), and the bias caused by interference can be positive or negative. The consequences of interference can be deleterious when clinicians consider erroneous results to establish a diagnosis, leading to unnecessary explorations or inappropriate treatments. Clinical laboratories and manufacturers continue to investigate methods for the detection, elimination, and prevention of interferences. However, no system is completely devoid of such incidents. In this review, we focus on the analytical interferences encountered in daily practice and possible solutions for their detection or elimination.

Key Words: Immunoassay, Hormone, Interference, Heterophile antibodies, Biotin
Received: February 7, 2021

Revision received: March 8, 2021

Accepted: July 21, 2021

\section{Corresponding author:}

Marie-Liesse Piketty, Pharm., Ph.D.

Assistance Publique Hopitaux de Paris, Department of Functional Explorations, Necker Enfants Malades Hospital, ParisCentre University, 149 Rue de Sèvres, 75743, Paris Cedex 15, France

Tel: +33-1-4449-4394

E-mail: marie.piketty@aphp.fr

\section{INTRODUCTION}

Immunoassays are widely used in clinical laboratories for a variety of hormone analyses. Since the first insulin immunoassay described by Berson and Yalow (which received the 1977 Nobel Prize in Medicine), immunoassays have evolved considerably [1]. However, with widespread adaptation of these techniques, several interferences have been identified. Immunoassays are susceptible to interference because of the complexities of the antigen ( $\mathrm{Ag}$ )-antibody ( $\mathrm{Ab}$ ) interaction occurring in a complex matrix [2]. Such interference leads to incorrect interpretation of immunoassay results, leading to unnecessary explorations or administration of inappropriate therapy.

Immunoassay design initially relied on the development of polyclonal Abs obtained from animal sources in a competitive format; In 1975, Köhler and Milstein [3] described the monoclonal Ab (mAb) development technique (which received the 1984 Nobel Prize in Medicine), leading to the development of non-competitive (sandwich) immunoassays where two different mAbs can recognize the same Ag in one incubation step. The sensitivity and specificity of immunoassays made it possible to detect and quantify analytes at extremely low concentrations, which was not possible with other clinical chemistry techniques. Along with the advantages of a rapid measurement time and fully automated instruments, the improved analytical performance led to immunoassays becoming a widely adopted technique in clinical laboratories.

Analytical systems have been developed to be more rapid 
and efficient with advantages of the automation evolution to meet the demands of an augmented workload and the need for rapid analysis. However, these advancements are associated with drawbacks such as the low specificity of direct steroid immunoassays. The systems have also become more reliable owing to improvements in immunoassay reagents and signal detection systems.

These advances have decreased, but not completely eliminated, the incidence of interference in immunoassays. Analytical errors from endogenous interferents still occur with some patient samples [4]. Interference might induce false-positive results, false-negative results, or both, which can simulate a seemingly coherent hormonal profile that might drive unnecessary explorations, inappropriate treatments, or a missed diagnosis.

Laboratory quality control efforts (i.e., compliance with regulatory and accreditation demands, instrument maintenance, internal and external evaluation programs) have an ultimate goal of rapidly obtaining reliable and accurate results. However, interferents in patient samples are not detectable by standard quality control procedures and are reproducible within a given analytical system [5]. Laboratory specialists must take a critical view of results and not blindly trust the instruments. Knowledge of physiology and normal variations in biological markers enables assessing whether discordance with previous results is acceptable, or for identification of an aberrant result in some cases. Precise understanding of the analytical principles and assay design is also necessary for the correct interpretation of laboratory results and suspicion of erroneous results.

In this review, we discuss the types of immunoassays commonly used in laboratories, the mechanisms involved in possible in vitro analytical interference, and the solutions and strategies employed to suspect and overcome such interference, including recently reported emerging interferences. Hormone concentrations modification by the pharmacological action of a drug is beyond the scope of this review and will not be addressed.

\section{METHODS USED IN HORMONE ASSAYS}

There are two main methodologies widely used in hormonology laboratories: immunoassay methods and mass spectrometry methods. In this review, we exclusively focus on immunoassays, which can be classified into competitive and non-competitive (sandwich) immunoassays.

\section{Competitive (limited reagent) immunoassays}

In competitive immunoassays, the analyte $(\mathrm{Ag})$ competes with a signal-labeled $\mathrm{Ag}$ (tracer) for limited quantities of Ab (Fig. 1A). After a washing step, the bound signal is produced and the analyte concentration in the sample is inversely correlated with the generated signal. These assays can be performed either simultaneously (the majority), where both the patient sample and labeled $\mathrm{Ag}$ are added at the same time, or sequentially, where the labeled $\mathrm{Ag}$ is added in a second step after allowing the $\mathrm{Ab}-\mathrm{Ag}$ reaction to reach equilibrium.

\section{Non-competitive/sandwich or "two-sites" (excess reagent) immunoassays}

In non-competitive immunoassays, the capture $A b$ is fixed on a solid phase, and then the analyte (in the sample) and labeled $\mathrm{Ab}$ (tracer) are added (Fig. 1B). The two Abs recognize different epitopes on the analyte. The capture and labeled Abs can be monoclonal, polyclonal, or both. After a washing step, the tracer signal is produced and the analyte concentration in the sample is directly correlated with the generated signal.

\section{Competitive versus sandwich assays}

The majority of hormone immunoassays are heterogeneous; thus, the choice of methodology for immune complex separation is specific to each reagent manufacturer and each analyte. In competitive and sandwich immunoassays, the capture $A b$ must be separated from the reaction mixture at the end of the reaction. This is facilitated either by a solid-phase coating of the capture $A b$ or by using a biotinylated $A b$ (or biotinylated Ag), which will be captured by a streptavidin solid phase. Other methods use a solid phase-coated Ab directed against the capture Ab specific to the analyte (separation step using a second $A b$ ).

Sandwich immunoassays are suitable for larger molecules [e.g., polypeptide hormones, pituitary hormones, parathyroid hormone (PTH), calcitonin, thyroglobulin (Tg), insulin, C-peptide, insulin-like growth factor 1 (IGF-1), proteins, anti-Müllerian hormone (AMH), inhibin], whereas competitive immunoassays are better suited for detecting smaller molecules because only one antigenic site will be recognized by one $A b$ [e.g., thyroid hormones T3 and T4 (either total or free), steroids, 25 hydroxy vitamin D] [6]. Many assays for Ab detection and quantification are also designed according to the "competitive" format [Ab to thyroid-stimulating hormone (TSH) receptor, anti-thyroid peroxidase, and anti-Tg].

Both competitive and sandwich immunoassays have their advantages and pitfalls. Competitive immunoassays are mandatory for small molecules but are susceptible to cross-reactions with precursors or metabolites of the analyte or with drugs, and to in- 


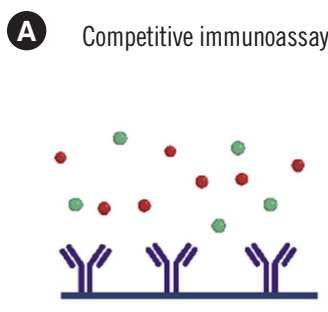

(1) Sample and labeled $\mathrm{Ag}$ added to capture Ab fixed on solid phase

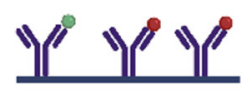

(2) Sample and labeled Ag compete for capture Ab

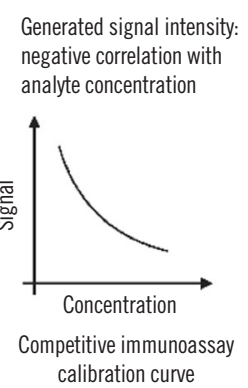

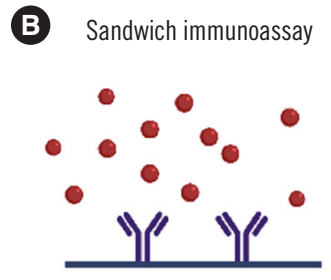

(1) Sample added to capture Ab fixed on solid phase

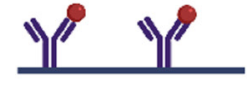

(2) Antigen binds to capture Ab

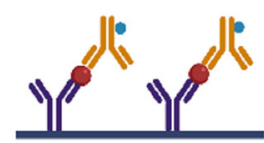

(3) Labeled Ab binding to another site on $\mathrm{Ag}$ and immunocomplex formation
Generated signal intensity: positive correlation with analyte concentration

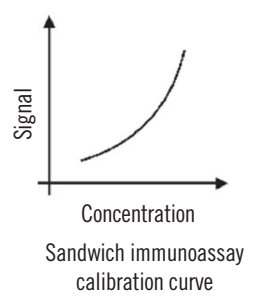

Fig. 1. Two types of immunoassays. (A) Competitive immunoassay. The sample is incubated with an anti-cortisol antibody (Ab) (for example), and a tracer (cortisol labeled with a measurable signal: enzyme, fluorescent, or luminescent compound isotope) is added. Competition occurs between the cortisol in the sample and the labeled cortisol for the Ab-binding sites. These cortisol molecules bound to the Ab are captured on a solid phase. Unlike sandwich assays, the higher the cortisol concentration in the sample, the lower the signal-labeled cortisol bound to the antibody and finally linked to the solid phase. (B) Sandwich immunoassay. TSH (for example) is "sandwiched" between two different antibodies: one is labeled with a signal to be measured (luminescent or fluorescent compound, enzyme, isotope) and the other one, named the "capture antibody," will allow the separation of the immune complexes on a solid phase. The higher the TSH concentration, the higher the signal linked to the solid phase will be.

Abbreviations: Ab, antibody; Ag, antigen; TSH, thyroid-stimulating hormone.

terference from endogenous Abs and biotin when the biotinstreptavidin complex is used to separate the immunocomplex. Sandwich immunoassays are usually more robust since Ab reagents are introduced in excess. Sandwich immunoassays also present higher specificity and a lower limit of quantification; however, these assays are prone to some interference due to endogenous Abs, biotin, and the hook effect, which is specific to the sandwich format.

\section{TYPES OF INTERFERENCE}

\section{Pre-analytical factors}

Obtaining reliable laboratory results begins at the sample collection stage. Pre-analytical conditions have to be respected, such as the tube type (serum vs. plasma, type of anti-coagulant for plasma, with or without a separating gel); time of collection for hormones with time-dependent concentrations (e.g., cortisol and testosterone concentrations are higher in the morning and estradiol concentrations depend on the day in the menstrual cy- cle); storage and transportation temperature [adrenocorticotropic hormone $(\mathrm{ACTH})$ at $+4^{\circ} \mathrm{C}$, renin at $20-25^{\circ} \mathrm{C}$; and the absence of hemolysis (insulin) [7-9]. Bilirubin and lipids can also interfere with immunoassays, depending on the immunoassay design and signal detection system.

Azides are commonly used as preservatives for long-term storage, but they have been shown to destroy peroxidase labels. EDTA is a powerful chelating agent that binds to the metallic ions of labels (e.g., europium) or to the cofactor required for some enzymes' activity (e.g., zinc for alkaline phosphatase) [10]. Since samples stored in EDTA require more caution than serum regarding the risk of signal interference, serum is the matrix of choice for many analytes.

\section{Cross-reaction/assay specificity}

The presence of molecules structurally related to the Ag within the biological sample might lead to a cross-reaction and unwanted recognition by the $A b$, leading to specificity problems. These cross-reactants can be either metabolites or precursors of the 
analyte or drugs (either native or drug metabolites). Some classical examples of such challenging interference are presented in Table 1, together with recent drugs leading to specificity problems such as fulvestrant (in estradiol immunoassays) and pegvisomant, a growth hormone $(\mathrm{GH})$ analog and receptor antagonist (in GH immunoassays).

Biochemical evaluation of menopausal status with accurate estradiol concentration measurements are needed for establishing the treatment strategy in patients with estrogen receptor-positive breast cancer. Fulvestrant is a selective estrogen receptor antagonist that triggers degradation of the receptor. In breast cancer patients, fulvestrant leads to marked cross-reactions in estradiol immunoassays because of structural similarities (the long half-life of fulvestrant leads to interference lasting for months in these patients) [11]. Likewise, the aromatase inhibitor exemestane is a structural analog of estradiol prescribed in breast cancer therapy. Biochemical evaluations of estradiol in exemestane therapy cause false-positive results in most estradiol immunoas- says because of cross-reaction with exemestane metabolites [12].

The presence of a cross-reactant can lead to inaccurate results depending on the assay format, with competitive immunoassays being the most susceptible to this problem. In a competitive immunoassay, the cross-reactant usually induces a false increase (except in one estriol immunoassay, owing to a particular design [13]). Notably, direct steroid immunoassays (without an extraction step of the sample with an organic solvent) can be affected by cross-reaction (e.g., cortisol metabolites, synthetic glucocorticoids in cortisol immunoassays) [14]. In testosterone concentration measurements, second-generation immunoassays avoid dehydroepiandrosterone sulfate (DHEAS) cross-reaction $[15,16]$. However, an extraction step prior to the immunoassay is required for samples from women and children to protect against other cross-reactants [17].

For molecules large enough to bear two unhindered specific epitopes, two-site sandwich assays exhibit superior specificity to that of competitive assays. Interference is less frequent in a sand-

Table 1. Common problems of cross-reaction and specificity in current immunoassays

\begin{tabular}{|c|c|c|c|}
\hline Analyte & Cross-reacting compound & Context & Reference \\
\hline \multicolumn{4}{|c|}{ Competitive immunoassays } \\
\hline $170 \mathrm{H}$ progesterone & $170 \mathrm{H}$ pregnenolone sulfate & Neonates (especially preterm) & $\begin{array}{l}\text { Wong, et al. } 1992 \text { [182] } \\
\text { Makela and Ellis, } 1988 \text { [183] }\end{array}$ \\
\hline \multirow[t]{2}{*}{ Cortisol } & 11 desoxy cortisol & $\begin{array}{l}11 \text { Hydroxylase defect } \\
\text { Metyrapone test }\end{array}$ & $\begin{array}{l}\text { Ward, et al. } 2017 \text { [26] } \\
\text { Hawley, et al. } 2016 \text { [184] }\end{array}$ \\
\hline & $\begin{array}{l}\text { Prednisone, prednisolone and } \\
\text { methylprednisolone }\end{array}$ & Corticoid therapy & $\begin{array}{l}\text { Ward, et al. } 2017 \text { [26] } \\
\text { Vogeser, et al. } 2017 \text { [185] }\end{array}$ \\
\hline \multirow[t]{3}{*}{ Estradiol } & Estrone sulfate & Hormone replacement therapy (oral administration) & Thomas, et al. 1993 [186] \\
\hline & Fulvestrant & Breast cancer therapy & Owen, et al. 2019 [11] \\
\hline & Exemestane metabolites & Breast cancer therapy & Mandic, et al. 2017 [12] \\
\hline Progesterone & Di-hydroprogesterone & Micronized progesterone therapy & Nahoul, et al. 1987 [187] \\
\hline Testosterone & Fetal and placental steroids & Females, children & $\begin{array}{l}\text { Taieb, et al. } 2003 \text { [188] } \\
\text { Honour, } 2010 \text { [17] }\end{array}$ \\
\hline Testosterone & DHEA-S & Females & Warner, et al. 2006 [189] \\
\hline T3 (either total or free) & Triiodoacetic acid & & Piketty, et al. 1996 [190] \\
\hline DHEAS & Pregnenolone sulphate & Pregnancy & Krasowski, et al. 2014 [191] \\
\hline \multicolumn{4}{|l|}{ Sandwich immunoassays } \\
\hline ACTH 1-39 & Fragments, precursor & Paraneoplastic tumors & Raff and Findling, 1989 [20] \\
\hline Insulin & Pharmacological analogs & Inappropriate injection leading to hypoglycemia & $\begin{array}{l}\text { Parfitt, et al. } 2015 \text { [22] } \\
\text { Giurgea, et al. } 2005 \text { [24] } \\
\text { Dayaldasani, et al. } 2015 \text { [23] }\end{array}$ \\
\hline \multirow[t]{2}{*}{ Growth hormone } & Pegvisomant & Acromegaly therapy & $\begin{array}{l}\text { Paisley, et al. } 2007 \text { [18] } \\
\text { Manolopoulou, et al. } 2012 \text { [19] }\end{array}$ \\
\hline & Placental GH & Pregnancy & Dias, et al. 2013 [192] \\
\hline
\end{tabular}

Abbreviations: ACTH, adrenocorticotropic hormone; DHEAS, dehydroepiandrosterone sulfate. 
Ghazal K, et al.

Hormone immunoassay interference
ANNALS OF

LABORATORY MEDICINE wich immunoassay because of double epitope recognition. However, its manifestation will depend on the epitopes involved in sandwich formation; if both the capture and signal Abs bind a structurally related cross-reactant, a false increase will occur (e.g., pegvisomant for some GH assays) [18, 19]. Conversely, if only one $\mathrm{Ab}$ (either the capture or signal $\mathrm{Ab}$ ) attaches to the structurally related cross-reactant, a false decrease will be obtained, because the sandwich complex will not be completed and the signal Ab will be washed away after the separation step [18]. In some cases, it is clinically important to detect precursors or fragments present in certain tumors, together with the intact form of the hormone such as ACTH [20, 21]. High specificity for intact pituitary ACTH 1-39 is not always desirable. Another example is insulin immunoassays, where recognition of insulin pharmacological analogs can be useful in the rare cases of surreptitious administration [22-24]. The lack of recognition of all hormone isoforms can also be deleterious in some cases such as TSH immunoassays that do not recognize variants present in some ethnic groups [25].

A lack of or too high specificity can, in some circumstances, lead to inaccurate results. Wide specificity can be of great value, depending on the clinical context, which will define the appropriate specificity; the choice of epitopes to be detected is crucial and will depend on the clinical utilization of the assay. Reagent manufacturers are continuously selecting new Abs to reduce specificity problems and improve their immunoassays [26]. In any case, appropriate interpretation of the result depends on the knowledge regarding assay specificity.

\section{The hook effect}

This phenomenon may occur in sandwich immunoassays when measuring very high hormone concentrations; the hook effect occurs specifically in progressive tumor pathologies, in which the magnitude of variation between the physiological and pathological concentrations can be extreme (such as in prolactinoma, thyroid carcinoma, and hydatiform moles). To our knowledge, the hook effect has never been described in cases of somatotropinomas (acromegaly) or corticotropinomas (Cushing disease), possibly because these tumors are rarely large enough to produce extreme hormone concentrations [27]. In two-site sandwich immunoassays, the excess Ag might prevent sandwich formation with the capture and signal Abs separately bound to the Ag and the signal Ab being washed away, resulting in an apparently lower concentration (Fig. 2). This could result in delayed diagnosis and treatment for serious conditions, or even misdiagnosis with serious consequences. For example, an unrecognized hook effect can result in erroneous diagnosis of a non-functioning pituitary tumor, subjecting the patient to unnecessary surgery instead of prescribing dopamine agonists (in the case of macroprolactinoma) [28]. The hook effect impacts only sandwich immunoassays, and sample dilution will reveal the presence of excess analyte; with serial dilutions, the concentration of the analyte will increase until two coherent successive dilutions are obtained. Manufacturers tend to use excess Abs or reduce the required sample volume to minimize possible Ab saturation and the frequency of the hook effect. Table 2 presents recent examples of reported cases of the hook effect for hormone concentration measurements.

\section{Interfering Abs}

Endogenous interfering Abs are highly heterogeneous in nature and in their interference mechanisms. The problem induced by endogenous Abs that can inhibit either the Ag-Ab complex separation (at the end of incubation in the reaction mixture) or the signal development will be addressed in subsequent sections (Their impact on these steps gives them the ability to affect mul-
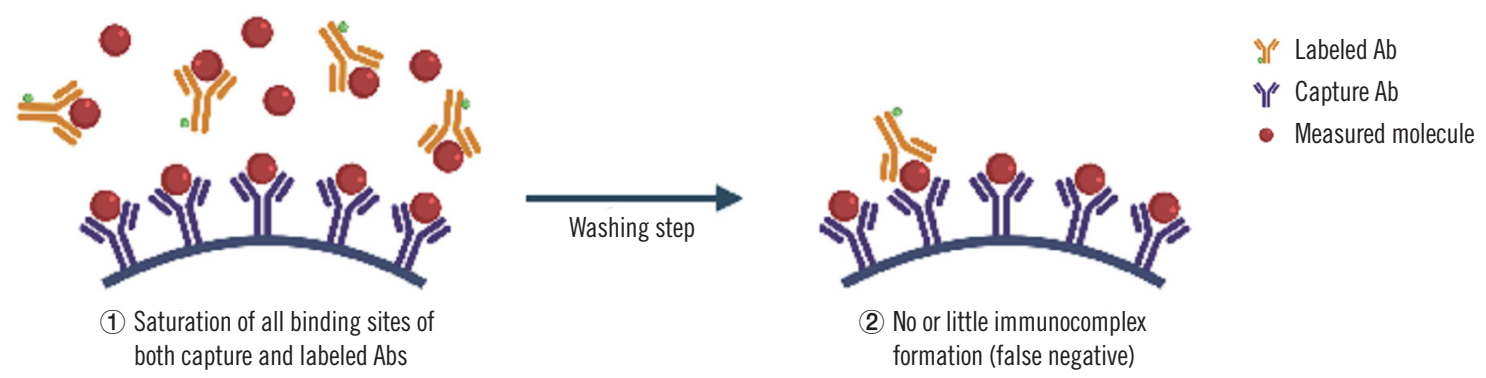

Hook effect in Sandwich Immunoassay

Fig. 2. The hook effect in sandwich immunoassays. The excess Ag saturates both capture and labeled Abs; no or little amount of the AbAg-Ab complex is formed, leading to false low results.

Abbreviations: Ab, antibody; Ag, antigen. 
tiple immunoassays simultaneously in a bidirectional way). This section discusses other interfering Abs, including those affecting immunocomplex formation or analyte recognition, directed against animal reagent Abs or the analyte itself.

Table 2. Examples of reported cases of the hook effect for hormone measurements

\begin{tabular}{|c|c|c|c|}
\hline Analyte & $\begin{array}{c}\text { Measured } \\
\text { concentration } \\
\text { before dilution }\end{array}$ & $\begin{array}{l}\text { Actual concentration } \\
\text { after serial dilution }\end{array}$ & Reference \\
\hline Prolactin & $164.5 \mathrm{ng} / \mathrm{mL}$ & $\begin{array}{l}26,000 \mathrm{ng} / \mathrm{mL} \\
\quad \text { (macroadenoma) }\end{array}$ & $\begin{array}{l}\text { Frieze, et al. } 2002 \\
\text { [28] }\end{array}$ \\
\hline Calcitonin & $182 \mathrm{ng} / \mathrm{L}$ & $450,000 \mathrm{ng} / \mathrm{L}$ & $\begin{array}{l}\text { Schiettecatte, et al. } \\
2016 \text { [193] }\end{array}$ \\
\hline Thyroglobulin & $\begin{array}{l}3.8 \mathrm{ng} / \mathrm{mL} \\
4.6 \mathrm{ng} / \mathrm{mL}\end{array}$ & $\begin{array}{l}207,855 \mathrm{ng} / \mathrm{mL} \\
140,462 \mathrm{ng} / \mathrm{mL}\end{array}$ & $\begin{array}{l}\text { Hillebrand, et al. } \\
2020 \text { [194] }\end{array}$ \\
\hline HCG & Low/normal & $\begin{array}{l}5,899,478 \mathrm{mlU} / \mathrm{mL} \\
\text { (gestational } \\
\text { trophoblastic disease) }\end{array}$ & $\begin{array}{l}\text { Cormano, et al. } 2015 \\
\text { [195] }\end{array}$ \\
\hline
\end{tabular}

Abbreviation: HCG, human chorionic gonadotropin.
Heterophile Abs and anti-animal Abs

Heterophile Abs are polyclonal Abs found in human samples that can react with assay reagent Abs obtained from different species. They may lead to false high (mostly) or false low results. Studies on the prevalence of this interference in immunoassays have yielded values ranging from $0.4 \%$ to $0.5 \%[29,30]$.

The definition of heterophile and human anti-animal Abs [HAAA; mostly human anti-mouse Abs (HAMAs)] is confusing and overlapping among studies, because some authors have used the term "heterophilic $A b$ " to refer to any endogenous interfering $A b$, regardless of the mechanism. Heterophile Abs are typically of human origin, endogenous, and weakly poly-specific Abs; they are considered to occur naturally and are able to react with Abs from multiple species. In contrast, HAAAs are monospecific, high-affinity Abs, which can appear after exposure to animals or animal products, viral or bacterial infections, in an autoimmune clinical context, or without any identified cause. Their interference mechanism is, however, similar to that of heterophile antibodies. In laboratory practice, the term "heterophile $A b$ " is typically used whenever an endogenous $A b$ is suspected

B Competitive immunoassay

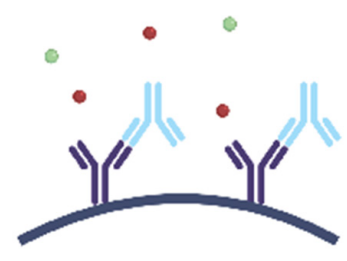

$$
\begin{aligned}
& \text { If'Capture Ab } \\
& \text { - Measured molecule } \\
& \text { - Labeled molecule }
\end{aligned}
$$
Ab (false positive)

Interfering Ab bridging capture and labeled Ab to form immune complex (false positive)

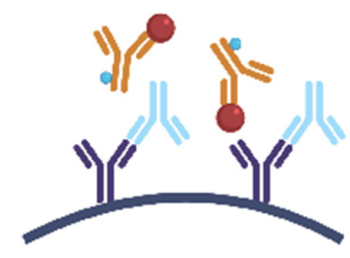

(2) Antibodies against Fab of capture Ab (false negative)

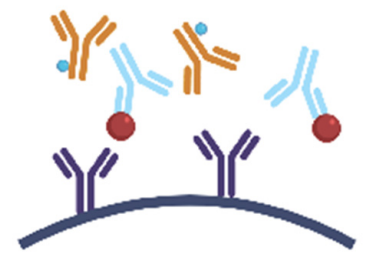

(3) Antibodies against analyte (false negative)
I." Labeled Ab
"Interfering Ab
- Measured molecule

Fig. 3. Mechanisms of Ab interference in immunoassays. (A) In sandwich immunoassays, the Ab can (1) cross-link the capture and detection Abs (false positive), and $(2,3)$ prevent the formation of the Ab-Ag-Ab complex by blocking the Abs or the analyte (false negative). (B) In competitive immunoassays, the $\mathrm{Ab}$ can block the capture $\mathrm{Ab}$ or the analyte giving false high results. Abbreviations: $\mathrm{Ab}$, antibody; $\mathrm{Ag}$, antigen. 
to bind to the assay Abs [29, 31]. Knowledge of previous exposure to diagnostic or therapeutic Abs is important; the term "heterophile" should theoretically be used only when there is no evidence of exposure to animal Ig [31, 32]. Heterophile Abs can be of the IgG, IgM, or IgA isotype. Although they bind mostly to the Fc region of the assay Abs, there are reports of these interfering Abs binding to other parts of the assay Abs (such as the idiotope or the hinge region) [33, 34].

The Ab interference mechanism varies depending on the assay design. In sandwich immunoassays, a heterophile Ab can form a bridge between capture and labeled Abs (cross-linking the two Abs), resulting in false-positive interference in most cases (Fig. 3A-1) [35]. Rarely, a heterophile Ab can prevent formation of the Ag-Ab complex by binding and blocking only one of the assay Abs, preventing binding of the analyte through steric effects, resulting in false-negative interference (Fig. 3A-2) [32, 36]. Although this interference mostly concerns sandwich immunoassays, in competitive immunoassays, the interfering Ab can also give false high results by blocking the capture Ab (thus decreasing the assay signal) (Fig. 3B) or false low results [37-39]. In rare cases, heterophilic $A b$ interference can affect multiple hormone immunoassays simultaneously [37, 39-41].

HAAAs differ from heterophile Abs by being theoretically specific to a species and having higher avidity. Anti-animal Abs (IgG, IgM, IgA class, anti-isotype, and anti-idiotype specificity) include human anti-mouse, anti-rabbit, anti-goat, anti-sheep, anti-cow, anti-pig, anti-rat, and anti-horse Abs, and those with mixed specificity [32]. HAAAs can be transient, lasting from a few days to several months or years [42, 43]. These arise because of iatrogenic and non-iatrogenic causes of exposure to animal Ags. The exposure can happen to a variety of workers, such as animal breeding facility workers, laboratory animal technicians, and butchers, as well as from pets and dietary sources [44, 45]. Since murine mAbs are used for medical purposes, HAMAs are the most commonly encountered interfering HAAA type.

The reported prevalence of HAAA interference of less than $1 \%$ might seem low, but the impact can be greater than expected when considering the prevalence of the disease being diagnosed based on the immunoassay results. Ismail [46] showed that at a $0.4 \%$ probability of analytical interference for subclinical hypothyroidism with a $2 \%$ prevalence (for both sexes at all ages), only $83 \%$ of the results are diagnostically correct, meaning that $17 \%$ of the cases will be falsely diagnosed.

There has been recent revolutionary progress in immunotherapies for treating cancers, autoimmune diseases, and other clinical conditions. As of December 2019, the United States Food and Drug Administration agency has approved 79 therapeutic mAbs [47]. This increases the possibility of Ab-related interference, because a therapeutic Ab can act as an Ag leading to the generation of HAMAs. Immune checkpoint inhibitors can induce real endocrine disorders such as dysthyroidism, hypophysitis, and adrenal insufficiency, and thus represent a crucial problem. The discordant clinical picture with laboratory results raises the question of possible interference in immunoassays, especially when the mAb used in treatment is not completely humanized; the probability of detecting HAAAs is theoretically $90 \%$ for a murine $\mathrm{mAb}, 40 \%$ for a chimeric $\mathrm{mAb}$, and $10 \%$ for a humanized therapeutic mAb [48, 49]. In 2010, Koshida, et al. [50] developed an assay for HAMA, and recorded $11.7 \%$ positive samples among inpatients and outpatients. A very small percentage of HAMAs will produce an erroneous result. However, the number of potential errors with clinical consequences is worrisome owing to the vast number of immunoassays performed [51]. For example, Jonklaas [52] reported a case of falsely elevated free thyroxin (FT4) concentration in a patient after starting treatment with checkpoint inhibitor murine mAbs for metastatic melanoma. Interestingly, heterophile Ab interference was recently reported in PTH and Tg immunoassays for three patients after the transfer of ex vivo-expanded natural killer cells [53].

\section{Rheumatoid factors (RFs)}

RFs can interfere with immunoassays via the same mechanisms as those of heterophile Abs. RFs are predominantly of the IgM isotype, which interact with the Fc part of human IgG but can also react with that of different species with variable affinity, although their affinity seems to be low with mouse IgG [54]. RFs are found in more than $70 \%$ of patients with rheumatoid arthritis and other autoimmune diseases. The RF concentration can also increase during infection with inflammation.

RFs can be measured in suspected samples and eliminated by different techniques. Astarita, et al. [55] reported a case of interference in $\mathrm{Tg}$ concentration measurements in a woman with differentiated thyroid cancer and a rheumatoid arthritis history, where detectable Tg became undetectable after eliminating RFs through polyethylene glycol (PEG) treatment. RF interference can affect multiple parameters simultaneously; Mongolu, et al. [56] reported the case of a 60-year-old male patient with a history of rheumatoid arthritis, who had high serum concentrations of luteinizing hormone (LH), follicle-stimulating hormone (FSH), sex hormone-binding globulin, prolactin, human chorionic gonadotropin (HCG), and TSH. They suspected assay interference and performed further tests after eliminating RFs, which revealed 
normal hormone concentrations.

In most cases, comparison with alternative immunoassay results is useful when suspecting $A b$ interference, as the interfering $A b$ is most potent with the Abs of a specific class/subclass or isotype, resulting in strikingly different results with different methods [57]. Dilution tests lacking linearity, use of heterophile blocking tubes (HBTs), and protein A pretreatment are also useful to demonstrate that a result is erroneous [39]. However, no single test can be used as evidence or to rule out an erroneous result [26].

To reduce such interference, manufacturers have developed some strategies such as inclusion of non-immune animal lg from the same species as reagent lgs, aggregated Ig, use of chimerized or humanized Abs, or two $F(a b)$ fragments instead of intact Ig on their solid phase [26, 29]. However, heterophilic Abs are highly heterogeneous in nature, their concentrations vary largely between patients, and no blocking reagent/method is completely successful in preventing such interference. Although the frequency of heterophilic $A b$ interference may be declining, recent reports concerning erroneously elevated concentrations of PTH, FSH, LH, and prolactin demonstrate that this type of interference can still occur with any immunoassay [58-60].

Anti-analyte Abs and macro-analytes

Prolactin

An $\mathrm{Ab}$ can bind to the analyte in vivo altering its half-life and physiological role, while preserving its antigenicity, or can interfere directly with the in vitro immunoassay. Circulating monomeric prolactin can bind to IgG Abs in vivo, resulting in an inactive form with a much longer half-life, now termed "macroprolactin," and giving higher prolactin concentrations in immunoassays. This can lead to the physician/gynecologist pursuing unnecessary explorations in approximately $4-10 \%$ of women [35, $61,62]$. The macroprolactin complex is a source of interference in prolactin immunoassays and commonly results in the misdiagnosis of hyperprolactinemia. Removal of macroprolactin by precipitation with PEG is an effective technique to identify such interference but is unfortunately not universally employed due to the manual nature of the procedure [63]. A possible explanation for the development of these anti-prolactin Abs is post-translational modifications that give rise to immunogenicity and the development of anti-prolactin autoAbs [64]. Another form of circulating prolactin is the result of auto-polymerization of prolactin in vivo, yielding large prolactin molecules that can be measured with different immunoassays. Macroprolactin can react in all prolactin immunoassays, albeit to different extents, which might be related to the degree to which the prolactin epitopes are exposed in the macroprolactin complex $[35,63,65]$. Clinical laboratories should implement a validated screening procedure to exclude macroprolactinemia in all patients presenting with hyperprolactinemia. PEG precipitation allows for the production of an Ig-free sample, which is effective in a variety of hormone immunoassays (prolactin, TSH, and FSH), resulting in at least $60 \%$ recovery. Since PEG precipitation is non-specific, some amount of the analyte is lost due to co-precipitation. PEG reduces solvent availability due to which proteins solubility is exceeded, leading to their precipitation [66]. However, the precipitation of IgA is only partial; a case of IgA macroprolactinemia with a falsenegative PEG screening test was reported [63]. Since the presence of macroprolactin can change over time, an assay to detect macroprolactinemia should be repeated and macroprolactin might still develop even if it has been excluded previously [67].

\section{Other macrohormones: macro-FSH, macro-LH, and macro-TSH} Similar to macroprolactin, macro-FSH, macro-LH, and macroTSH can be identified, although they are less common. MacroTSH was detected in $0.17 \%$ of infertile women with the PEG screening test, although the pathogenesis was not fully clear $[68,69]$. Commercial TSH immunoassays recognize macroTSH, resulting in a false diagnosis of hyperthyrotropinemia [35, 69]. PEG precipitation, dilution, and recovery tests could be useful in detecting this situation [70]. This finding has also been observed in euthyroid neonates due to transplacentally transmitted maternal anti-TSH Abs [71, 72].

\section{Thyroglobulin (Tg)}

In Tg immunoassays, the binding of Tg to an anti-Tg autoAb prevents the formation of many sandwich immune complexes with the assay Abs, which can underestimate Tg concentrations (Fig. 3A-3); anti-Tg Ab interference is the most serious problem currently limiting the clinical utility of Tg immunoassays [73]. Current guidelines mandate that every Tg immunoassay include anti-Tg testing, and the indirect Tg recovery approach can also be useful to detect interference, regardless of the cause [73-75].

\section{Insulin}

Insulin auto-immune hypoglycemia is an under-recognized pathology, which is common in Japanese patients (Hirata's disease) but rarer in Caucasians [76]. Anti-insulin autoAbs have heterogeneous clinical and analytical consequences [77]. These Abs are a cause of misleading and discordant results between different insulin immunoassays (with either highly elevated or 
normal results). Assaying for insulin Abs is therefore needed for the differential diagnosis of hypoglycemia in non-diabetic patients [78].

\section{Fibroblast growth factor 23 (FGF23)}

The most frequent heritable disease involving FGF23 is a variant in the phosphate-regulating endopeptidase homolog $X$-linked (PHEX) gene, causing $X$-linked hypophosphatemia $(X L H)$, with a clinical presentation of rickets/osteomalacia, growth retardation in children, demineralization, and bone pain. This loss-offunction variation leads to the upregulation of FGF23 production from the bone and resultant kidney phosphate wasting. Recently, the anti-FGF23 Ab burosumab emerged as a breakthrough therapy for $\mathrm{XLH}$, targeting the chronic upregulation of FGF23. Burosumab is a fully human IgG1 mAb that binds intact FGF23. In vitro, burosumab inhibits recognition of the intact FGF23 molecule by preventing binding of one or both reagent Abs in sandwich two-site assays, indicating that the intact FGF23 molecules were no longer recognized in vitro [79].

\section{Free thyroid hormones}

The interfering anti-analyte Ab can also bind to the labeled analyte in vitro in competitive immunoassays. In one-step free thyroid hormone immunoassays, the presence of thyroid hormone autoAbs may induce spuriously elevated results (Fig. 3B-2). Immunoassays show diverse sensitivities to this pitfall, inducing variable magnitudes of interference [70, 80-82]. In vivo, the free thyroid hormone $\mathrm{Ab}$ seems to behave like another endogenous binding protein. The frequency of anti-T4 and anti-T3 autoAbs specifically relates to autoimmune thyroid disorders such as Hashimoto thyroiditis and other autoimmune diseases (e.g., lupus erythematosus, vitiligo) [80, 83-86]. These autoAbs can be induced by interferon- $\alpha$ therapy or can be transient and associated with Epstein-Barr-virus infection [87, 88]. Radiolabeled T4 (or T3) incubation followed by PEG precipitation can be useful when suspecting this type of interference [81, 82, 84].

\section{Interference affecting immune complex separation}

To help separate the reagent Abs from the reaction mixture, the streptavidin-biotin interaction is a rapid, efficient, and convenient method. The biotinylated Ab or Ag is separated on a streptavidin-linked solid phase, and this method has been widely adopted by many manufacturers. Any interferent that prevents the separation of immune complexes, will affect this interaction and potentially disturb multiple immunoassays. Either biotin or antistreptavidin Abs (ASA) can be involved in the mechanism of this type of interference.

The biotin problem

Biotin interference has been recognized for decades, but only in the context of rare hereditary metabolic disorders [89]. However, in the last four years, the combination of the widespread use of streptavidin-biotin technology, and the more frequent therapeutic or non-therapeutic use of supraphysiological doses of biotin have led to numerous reports of erroneous hormoneand non-hormone immunoassay results [90-93]. Biotin can inhibit immune complex separation, leading to opposite erroneous results of falsely elevated or depressed hormone concentrations in competitive or sandwich immunoassays, respectively, using techniques involving streptavidin-biotin separation [90, 92, 94]. This bidirectional behavior with opposite effects may mimic an endogenous endocrine pathological condition, representing a special challenge for endocrinology assays: results seemingly consistent with a biochemical diagnosis of hyperthyroidism can be obtained indicating a "perfect storm" [falsely elevated concentrations of FT4, free T3 (FT3), anti-TSH receptor Ab, and falsely lowered TSH concentration] [91, 92]. Vitamin D intoxication, testosterone-producing tumors, hyperandrogenism, hypercorticism, or PTH suppression have also been reported as "fake news" related to high biotin intake [95-100]. Conversely, some real endocrine disorders, including primary hypothyroidism, may be missed because of biotin distortion of the assays lowering the elevated TSH concentration [89, 101, 102].

Biotin therapy can be prescribed in dermatology for the treatment of various hair, nail, and skin disorders [103]. However, there is limited clinical evidence on its efficiency, except in biotin deficiency, which is a very rare situation since biotin recommended intake of $30 \mu \mathrm{g} /$ day is easily obtained from a normal, balanced diet [104]. Over-the-counter biotin supplements with moderately high doses (1-30 mg/day) are widely available and are now glamorized by popular media. Despite limited benefits for the treatment of hair loss or skin and nail health, the popularity of biotin appears to be important [105]. Most patients fail to mention taking this supplement to their physician, because it is not seen as a "real treatment," and some patients are not aware of the composition of the dietary supplement. Since February 2019, the European Medicines Agency imposed including a warning message concerning the risk of erroneous laboratory results, which must accompany any biotin supplements containing biotin dose higher than $150 \mu \mathrm{g}$ (popular vitamin cocktails, containing the usual $30 \mu \mathrm{g}$ recommended daily intake, will not induce any in vitro laboratory distortion with any assay) [106]. 
The worldwide prevalence of high-biotin supplement use is not well-known but seems to be country-dependent. Some studies have evaluated the biotin concentration in patient samples from different countries. A study quantifying biotin in plasma samples from emergency department patients in the USA showed that $7.4 \%$ of samples had a biotin concentration at or above $10 \mathrm{ng} /$ $\mathrm{mL}$ (considering a low threshold, above which interference will occur for the most sensitive immunoassays) [107]. In Australia, $0.8 \%(4 / 490)$ of patients sampled presented with a biotin concentration above $10 \mathrm{ng} / \mathrm{mL}$, whereas in the Netherlands, this percentage was estimated to be $0.2 \%[108,109]$. In the UK, no patients presented with a biotin concentration above $2.5 \mathrm{ng} / \mathrm{mL}$ in a group of 524 patients examined in 2020 [110].

Recent therapeutic protocols involving very high doses of biotin (300 mg) for progressive multiple sclerosis have highlighted the biotin problem in the last four years [111]. Since the most recent studies (by the end of 2020) showed the ineffectiveness of these very high doses for progressive multiple sclerosis, with a risk of erroneous laboratory results and associated negative consequences, these protocols will now be abandoned [112, 113]. Lastly, hospital departments specialized in the detection of inborn errors of metabolism use biotin in their protocols for several biotin-responsive medical conditions such as biotinidase deficiency, holocarboxylase synthetase deficiency, and biotinthiamine basal ganglia disease, with high biotin doses being prescribed [102, 114-116]. The biotin-associated risk is relevant in neonatal care, as biotin can be empirically (and temporarily) prescribed for neonatal epileptic encephalopathy [117].

For susceptible methods, the magnitude of error is proportional to the free biotin concentration in the sample; for very high doses of biotin, extreme pathological results may be recorded [118]. The most problematic situations are high doses administered for inborn errors of biotin metabolism, multiple sclerosis, and kidney failure, since biotin is mostly eliminated through the kidneys [99, 101, 119, 120]. With moderately high intake such as $10 \mathrm{mg}$ (for cosmetic purposes), the extent of analytical error is less remarkable as far as endocrine assays are concerned, but these doses remain a main source of confusing erroneous results. The major determinants of such errors for susceptible immunoassays are the biotin dose, time elapsed since last intake, and kidney function if altered. The maximum biotin concentration is observed approximately 1.5 hours after intake, and the half-life of biotin is 15 hours on average [121-124]. The susceptibility of different immunoassays involving streptavidin-biotin separation is also highly variable.

Different strategies have been proposed to minimize the risk associated with biotin for susceptible methods [125, 126]. Each laboratory should evaluate this risk according to methods used and specific recruitement (e.g., inborn errors of metabolism) [90]. The reformulation of immunoassays for biotin-resistant methods is successfully progressing, but many biotin-susceptible methods remain in widespread use [127].

While waiting for these improvements, public education and patient awareness of this issue are necessary. Because of this new situation, a component that can interfere with laboratory assays is continually being absorbed by a significant number of patients. Therefore, inquiry about biotin intake has become a key question. Patients who need laboratory assays should be notified to refrain from taking any supplement and allow several hours or days to "wash out" any residual biotin. Since the washout period needed will vary according to the assay performed, no single recommendation can be given for the time of washout [93, 122].

In patients with inborn errors of metabolism, biotin administration cannot be stopped, and in case of emergencies, it is not possible to wait for hours or days for biotin clearance; therefore, a contingency procedure must be established by the laboratory for these cases if the methods in use are susceptible to biotin interference [118].

Not all laboratories have the capability for biotin measurements, making it difficult to identify supra-physiological biotin intake; dilution tests and neutralization assays can help when suspecting this problem in a patient [120, 128, 129]. Some biotin-sensitive tests have been used as "biotin-detecting tests," (e.g., false high testosterone measurements in women, false high estradiol measurements in men) [130]. Once biotin interference is identified, it should raise the possibility of other affected results for this patient.

\section{ASAs}

ASAs in a patient's serum can cause the same bidirectional interference as found for biotin (i.e., falsely lowered in sandwich immunoassays and falsely increased in competitive assays). Unlike biotin, this interference is endogenous and is thus suspected to be non-transient. Given the possibility of interference for an extended time, cautioning the patient is necessary to provide information on the potential effect of this Ab on future medical examinations and to avoid the risk of future inappropriate treatments or investigations [131]. The seroprevalence of ASA seems to be higher than previously thought [132, 133]. Interference analysis in samples from 42 patients presenting with discordant thyroid assay results with a streptavidin-biotin methodology, 34 cases 
were found to be due to ASA [133]. In another study involving an anti-cyclic citrullinated peptide assay, $0.6 \%$ of the patients presented with a false-positive result due to the presence of ASA [134]. The mechanism of appearance of this Ab is still not elucidated. Streptavidin is produced by Streptomyces avidinii, a soil microorganism, and the circumstances that could lead to immunization are unknown. Based on the cases reported to date, the interferent will have a more pronounced effect on competitive immunoassays than on sandwich immunoassays; for example, FT3 and FT4 concentrations could be overestimated, whereas the TSH concentration could be apparently lowered, but not fully suppressed, as should be recorded in a real hyperthyroid patient sample. This Ab is less potent than biotin (with extremely high affinity for streptavidin, and higher than any AgAb binding). The lack of TSH suppression, associated with dramatically high "thyroid hormone" concentrations, will be noticed and evoke the syndrome of inappropriate thyrotropin secretion [131, 135-137]. By affecting a common step in immunoassays, as for biotin, multiple erroneous results can be recorded [131, 133, 137, 138].

\section{Interference affecting signal generation or quantification}

Rarely, the affected element in the immunoassay is the molecule that is supposed to generate the signal to enable quantification of the analyte. In some patients, an interferent present in vivo will inhibit the production of a measurable signal. For example, interference from the ruthenium signal led the manufacturer to modify and improve the ruthenium label and linker, as well as to add Ab polymers to block anti-ruthenium substances. The interfering factor could be an anti-ruthenium Ab or some unidentified substance [139, 140-143]. The anti-ruthenium component diminishes the amount of signal, resulting in false high or false low analyte concentrations, depending on the assay format. The magnitude of interference in competitive immunoassays (particularly FT4 and FT3) seems to be more important than that in sandwich immunoassays, indicating that the thyroid profile may evoke the syndrome of inappropriate TSH secretion [140, 142, 143]. When the presence of an anti-ruthenium $\mathrm{Ab}$ is confirmed, the origin of the immunization is not known. Buijs, et al. [140] proposed that anti-ruthenium Abs might be induced by the intake of ruthenium from the food chain or following exposure to residues on clothing (as ruthenium is used in the dying industry). It is also possible that the immune reaction against ruthenium (or ruthenium binding to the immunoassay reagent) is coincidental.

Other cases of interfering Abs directed against other labels have been sporadically reported in competitive assays using method-specific labels [144, 145]. These include falsely elevated androstenedione concentrations owing to Abs against the horseradish peroxidase label and erroneous estradiol and estriol concentrations due to anti-bovine alkaline phosphatase Abs, which can induce both positive and negative interferences because of the heterogeneity of available epitopes. Synthetic alkaline phosphatase (asfotase alfa) is a pharmacological recombinant alkaline phosphatase that is approved as the first therapy for hypophosphatasia, a rare inherited disease; a patient taking asfotase alfa will show a false low testosterone concentration in alkaline phosphatase-conjugated immunoassays. The proposed mechanism is that elevated phosphatase is not sufficiently removed during the washing step, and a falsely elevated signal will be produced, translating to a false low testosterone concentration because of the competitive design [146]. Fluorescein, used for ophthalmologic angiography examination, can also disturb fluorescent signal measurement in immunoassays involving a fluorescence measurement [147, 148].

\section{Other conditions that affect immunoassays}

The presence of particular proteins within the biological sample can disturb Ag-Ab binding and the awaited equilibrium and can induce laboratory test distortion.

\section{Monoclonal gammopathies}

"Paraproteins," specifically monoclonal lgs, can affect Ab binding and cause interference in TSH immunoassays, either by hindering the recognition of the Ag by binding to an idiotope of a reagent $A b$ or by behaving like a heterophilic $A b[149,150]$. The interference caused by these mAbs can be transient and is method-specific [150, 151]. HBT can efficiently remove these mAbs or can fail to reduce such interference [150-152]. Dilution tests may or may not be efficient in demonstrating the presence of interference [150, 152, 153]. A recent study demonstrated complex interference in some 25-hydroxy $(\mathrm{OH})$ vitamin D immunoassays in eight patients, involving paraproteins (IgG, IgM, or IgA) [154]. An effect of the dissociation agent (added to release $25-\mathrm{OH}$ vitamin $\mathrm{D}$ from its binding proteins), leading to precipitation, is evoked in the presence of the monoclonal component. This underlines the complexity of some interfering mechanisms, although simple PEG precipitation was found to be effective in removing the interference. The extent of interference seems to correlate with the concentration of the monoclonal component in some case reports [152, 155]. 
Binding proteins and free hormone measurements

Free hormone measurements are aimed at avoiding the influence of binding proteins and to obtain a better estimate of hormone actions compared with total hormone measurements. Although free thyroid hormone assay accuracy has been greatly improved in recent decades owing to the improvement in methodologies and tracers, their fragility remains evident for some patient groups such as patients with non-thyroidal illness (NTI), pregnancy, familial dysalbuminemic hyperthyroxinemia (FDH), and those presenting with thyroid hormone $\mathrm{Ab}$ (see the anti-analyte Abs section) [156]. The first two conditions (NTI and pregnancy) represent an analytical challenge because of the large, adaptive modifications of binding proteins, and free thyroid hormone estimates in these conditions remain a subject of debate [156]. FDH is a dominantly transmitted condition, in which an albumin variant is present with increased affinity for T4 (approximately 60 -fold). This syndrome does not cause disease, is associated with increased circulating total T4 concentrations, and is a source of spuriously elevated FT4 concentrations (possibly associated with elevated FT3 concentrations) [157]. Current free thyroid immunoassays frequently produce artifactual results, although with varying susceptibility, irrespective of a twostep or a one-step design $[158,159]$. The prevalence of FDH in the Caucasian population is estimated at 1 in 10,000 patients with the prevalence in patients of Hispanic origin being much higher (1.0-1.8\%), whereas this condition was reported to be extremely rare in Japan [160-162]. The $\mathrm{R} 218 \mathrm{H}$ albumin variant is the most frequent in FDH, although R218P and R218S can also be detected. FDH can mimic the biochemical picture of inappropriate TSH secretion (whether due to resistance to thyroid hormone or to $\mathrm{TSH}$-secreting pituitary adenoma) and seems to be an underdiagnosed entity; therefore, strategies have been established to avoid this pitfall [163, 164]. FDH can be identified by radiolabeled T4-binding electrophoresis and albumin gene sequencing [157].

Free testosterone concentration measurements are very challenging, and direct methods using an "analogue" tracer are a subject of caution and not widely recommended in clinical guidelines. Equilibrium dialysis and ultrafiltration methods are considered the gold standards to separate the bound form from free hormone. However, these methods are labor-intensive and present many technical issues; further, they lack common reference ranges and are not widely adopted in routine clinical laboratories [165, 166]. Several equations have been proposed to estimate the calculated free testosterone concentration in both men and women [166].

\section{Complement}

Negative complement interference can cause an increase in AMH concentrations in stored sera as compared with the results in fresh sera [167]. An interaction between complement fraction $\mathrm{Clq}$ and the immobilized anti-AMH capture Ab is followed by activation of the complement cascade pathway, with C3 cleavage and C3b deposition. The steric hindrance from this complex prevents AMH binding to the capture Ab. This assay is particularly susceptible due to the use of the IgG2a isotype as the capture Ab since this Ig has potent complement-activating abilities [168]. This problem is now avoided with the use of EDTA samples or EDTA-containing buffers to pre-dilute the sample, which reduces interference from calcium-modulated complement activation.

\section{CIRCUMSTANCES OF SUSPICION OF INTERFERENCE IN CLINICAL LABORATORIES}

Analytical artifacts must be considered in one or more of the following situations [10]: (1) lack of coherence with the clinical presentation and other investigations, such as a thyrotoxic biochemical profile in a clinically euthyroid patient, undetectable $\mathrm{FSH} / \mathrm{LH}$ in a young patient who has completed puberty with no signs of gonadotrophin deficiency, or normal prolactin in a patient with a known prolactin-secreting tumor [28]; (2) extremely unusual analyte concentrations, even in pathological states; (3) disrupted normal physiological regulatory feedback loops, evoking, for example, the very rare syndrome of inappropriate TSH secretion [163]; (4) inconsistent laboratory results obtained by different analytical methods, since the analytical errors are often method-dependent (notably for the streptavidin-biotin separation methods or signal-specific methods [57, 142]); (5) different results from anterior assays without any possible explanation, such as therapeutic-induced evolution.

Cases in which the results are falsely normal or slightly abnormal, although clinically plausible, are more difficult to detect [30, 51]. Laboratories must pay special attention to certain patient groups (e.g., those with hereditary disorders or autoimmune disorders, and those receiving immunotherapy or neurosurgery). Some external quality assessment schemes have specifically focused on some of the interference types reviewed herein (e.g., macroprolactin, pegvisomant therapy, proopiomelanocortin, HCG hook effect, and biotin) to raise awareness on these problems $[5,95,169]$. 


\section{SOLUTIONS IN THE FACE OF SUSPECTED INTERFERENCE}

When laboratory specialists suspect interference, different approaches are possible. These approaches are general and do not always identify the exact nature of the interfering agent, wher- eas others are more specific. The first question to answer is: "is there interference?"

Repeating the measurements and then questioning the complete assaying process is the starting step.

Strategies and algorithms have been defined, either in general or dedicated to thyroid function, Tg, or PTH assays [2, 31, 75,

Table 3. Troubleshooting the most frequent types of immunoassay interference

\begin{tabular}{|c|c|c|c|}
\hline Interference type $^{\dagger}$ & Error type & Identification & Troubleshooting \\
\hline \multicolumn{4}{|l|}{ Method-specific interference } \\
\hline Biotin & $\begin{array}{c}\text { Competitive assay: } \uparrow \\
\text { Sandwich assay: } \downarrow\end{array}$ & $\begin{array}{l}\text { Patient's file } \\
\text { Adsorption if validated } \\
\text { Dilution }\end{array}$ & $\begin{array}{l}\text { Withdraw biotin if possible, and obtain a new } \\
\text { sample } \\
\text { Test with an alternative method }\end{array}$ \\
\hline Anti-streptavidin antibody & $\begin{array}{l}\text { Competitive assay: } \uparrow \\
\text { Sandwich assay: } \downarrow\end{array}$ & Adsorption if validated & Test with an alternative method \\
\hline $\begin{array}{l}\text { Signal-specific antibody interference (anti- } \\
\text { ruthenium, anti-alkaline phosphatase) }\end{array}$ & $\begin{array}{c}\text { Competitive assay: } \uparrow \\
\text { Sandwich assay: } \downarrow\end{array}$ & Alternative method comparison & Alternative method needed \\
\hline Fluorescence signal & $\uparrow$ or $\downarrow$ & Fluorescein injection & Obtain a new sample after washout \\
\hline Alkaline phosphatase label & $\uparrow$ or $\downarrow$ & $\begin{array}{l}\text { Recombinant alkaline phosphatase } \\
\text { therapy }\end{array}$ & Obtain a new sample after washout, if possible \\
\hline \multicolumn{4}{|l|}{ Common interference } \\
\hline Hook effect (prolactin, HCG, Tg, calcitonin) & $\downarrow$ & Progressive dilutions & Two coherent successive dilutions \\
\hline Cross-reaction & $\begin{array}{l}\text { Competitive assay: } \uparrow \\
\text { Sandwich assay: } \uparrow \text { or } \downarrow \\
\text { (depending on specificity } \\
\quad \text { characteristics) }\end{array}$ & Patient's file, therapeutic information & $\begin{array}{l}\text { Appropriate interpretation } \\
\text { LC-MS/MS control (steroid assays) }\end{array}$ \\
\hline Macro analyte (prolactin, TSH, FSH, LH) & $\uparrow$ & $\begin{array}{l}\text { PEG precipitation } \\
\text { Recovery test } \\
\text { Gel filtration chromatography }\end{array}$ & $\begin{array}{l}\text { Appropriate interpretation and percent recovery } \\
\text { post-PEG }\end{array}$ \\
\hline Anti-insulin Ab (insulin assay) & $\uparrow$ or normal & Assay anti-insulin Ab & \\
\hline Anti-Tg Ab (TG assay) & $\downarrow$ & Assay anti-Tg & Control TG with LC-MS/MS, if available \\
\hline Burosumab therapy (intact FGF23 assay) & $\downarrow$ & Patient's file, therapeutic information & C-terminal FGF23 assay, if available \\
\hline Heterophile Ab, HAAA, RF (all assays) & $\begin{array}{l}\text { Mostly } \uparrow \\
\downarrow \text { possible }\end{array}$ & $\begin{array}{l}\text { Dilution test } \\
\text { HBT pretreatment } \\
\text { PEG pretreatment } \\
\text { RF assay } \\
\text { RF adsorbent } \\
\text { Adding non-immune Ig } \\
\text { Patients' file: looking for immunotherapy, } \\
\text { auto-immune context }\end{array}$ & Alternative method needed \\
\hline Gammopathy (all assays) & $\stackrel{\uparrow}{\downarrow \text { possible }}$ & $\begin{array}{l}\text { Dilution test } \\
\text { HBT pretreatment } \\
\text { PEG pretreatment } \\
\text { Protein electrophoresis }\end{array}$ & Alternative method needed \\
\hline $\begin{array}{l}\text { FDH, thyroid hormone autoantibody (FT4, FT3 } \\
\text { assays) }\end{array}$ & $\uparrow$ & Specific assay & $\begin{array}{l}\text { Notify in patient's file, alternative methods } \\
\text { needed }\end{array}$ \\
\hline
\end{tabular}

${ }^{\dagger}$ Interferences are either method-specific or common to all immunoassays (although errors of different magnitudes are recorded among the different methods). Abbreviations: Ab, antibody; HAAA, human anti-animal antibody; FDH, familial dysalbuminemic hyperthyroxinemia; FGF, fibroblast growth factor; FSH, follicle stimulating hormone; FT4, free thyroxine; FT3, free triiodothyronine; HBT, heterophile blocking tube; LC-MS/MS, liquid chromatography coupled to tandem mass spectrometry; LH, luteotropin hormone; PEG, polyethylene glycol; RF, rheumatoid factor; TSH, thyroid stimulating hormone; Tg, thyroglobulin. 
170-172]. The most recent strategies consider the biotin problem $[31,170]$. Each laboratory must validate the interference testing protocol for each immunoassay, as some methods are not valid after HBT or PEG pretreatment [173]. Methods involving a second Ab separation step prohibit the use of any blocking agent containing a mouse component [174]. Negative controls (and positive controls if available) are also needed.

A troubleshooting list is proposed in Table 3. This list supposes that method-specific interference or those related to specific situations have been identified, such as biotin treatment or new therapies. A useful approach could be to add a warning of a specific interference to remind clinicians of a possible pitfall or limitation of the assay (e.g., burosumab in the FGF23 analysis report). When possible, a new sample obtained after a washout period will be needed if an exogenous interferent is identified in the therapeutic file of the patient.

Among the different interference types, cross-reactivity is more or less foreseeable. This is mentioned in the reagent package insert, because cross-reaction from closely related molecules is usually tested by the manufacturer (although cross-reaction might be studied with a single, clinically irrelevant concentration). When a cross-reaction is suspected, appropriate interpretation of the result is helpful. In contrast, the presence of endogenous Abs is unpredictable, sporadic, and may induce complex analytical interference and inaccuracy [153].

Measuring an analyte using another method is very useful and essential, provided that the methodology used is different; this implies that an alternative method is available, for example in nearby laboratories. For steroid immunoassays, liquid chromatography coupled to tandem mass spectrometry (LC-MS/MS) will be the most appropriate control method.

Serial dilution of the sample is the simplest approach when interference is suspected (or for a hook effect). This could be an orienting assay and an adapted diluent must be used. Some immunoassays do not support sample dilution because of the matrix effect or because they "resist" dilution (e.g., free thyroid hormone assays) [175]. When applied, the dilution test will demonstrate negative or positive interference. However, it can be challenging to interpret dilution test results, as some samples with heterophile Abs can give a linear response (falsely confirming the original results) or a nonlinear response (potentially causing false confirmation of suspected interference) [29, 176]. A dilution test introducing animal serum or Ig (from the same species) can be useful [177].

No single test can identify or rule out interference from an endogenous $A b$. Identifying $A b$ interference might involve the use of HBTs (Scantibodies Laboratory, Santee, CA, USA), dilution test, RF-absorbents, PEG precipitation, and protein A and G preadsorption or the addition of animal serum or Ig (see Sturgeon [2] for a description of the protocols). The use of three simple tests (dilution test, HBT pretreatment, and PEG precipitation) could identify interference in $90 \%$ of suspected samples [153].

Samples from patients with a known history of rheumatoid arthritis or other autoimmune diseases associated with RF presence can help determine the cause of interference. Some commercial assays can detect HAMA-positive samples [178]. Notably, none of these commercial assays can detect all HAMA clones; thus, negative results based on these assays do not exclude the presence of an interfering HAMA [179].

Biotin interference is method-specific and can be simply overcome by comparing the results with those of a different separation methodology. The neutralization of biotin or ASA can be obtained with the aid of a high-capacity streptavidin solid phase [120, 128, 129, 180]. Other particular approaches are as follows:

- Heterophilic Abs are found in serum, plasma, or whole blood. Such interference is not found in urine; thus, discordant results with urine, for molecules eliminated in the urine, are an excellent way to detect this interference (HCG, cortisol) [177].

- A comparison of results obtained in newborns (e.g., elevated TSH screening result) with those observed in the mother can be helpful [71].

- Simultaneous measurements of procalcitonin can be useful to exclude a falsely elevated calcitonin result due to heterophilic Ab interference [181].

Precise identification of the interferent may require a specialized laboratory. For example, FDH requires a specialized technique using radiolabeled $\mathrm{T} 4$ capture by serum protein and albumin gene sequencing. Manufacturers can also help identify an interference.

\section{FUTURE PERSPECTIVES}

Improvements in assay design, Ab structure and specificity [196], and signal generation and detection, with an increasing number of assays developed to detect more molecules, have made immunoassays one of the most used techniques in clinical laboratories. However, there has also been a trend to simplify methods to facilitate automation, and new innovative therapies result in new interferences.

Some of the major specificity problems in competitive assays are related to the measurement of steroids and structurally related compounds. Therefore, many laboratories have started 
Ghazal K, et al.

Hormone immunoassay interference
ANNALS OF

LABORATORY MEDICINE using LC-MS/MS for the quantification of these analytes, although these methods are more expensive and technically demanding than immunoassays. LC-MS/MS avoids main specificity problems and also provides multi-parameter quantification in the same analytical session, allowing for steroid profiles to be generated with a dramatically reduced sample volume, which is valuable for newborns and infants. Unfortunately, these powerful and reliable measurements are not yet adapted to high-throughput sandwich assays. As protein and macromolecule assays with LC-MS/MS become more amenable, the use of immunoassaybased measurements may decline to improve specificity and robustness with respect to immunological interference, notably for some critical assays such as $\mathrm{Tg}$ as a major biomarker for the follow-up and management of differentiated thyroid cancer [75]. While waiting for these improvements, immunoassays, despite their drawbacks, will still be in general use, at least for a few years, and the problem of immunoassay interference will persist.

Laboratory knowledge plays a central role in highlighting possible interference. When a clinician deals with unexpected or incoherent results regarding patient conditions, a strong interface with laboratory specialists facilitates the rapid identification of incoherent results. Informing the clinical staff of the ever-present possibility of unexpected sporadic interference, notably from an endogenous $A b$, is needed [2].

When facing unknown interference, which might require more deep and specialized investigations, feedback from laboratory to manufacturers enables the manufacturers to actively search for a solution to the emerging problem and to keep improving the immunoassay robustness with respect to the risk of interference. Granting laboratory specialists access to the clinical and therapeutic records of patients is important when they suspect and try to detect interference. Specifically, the notion of biotin or a specific therapy has become a key question. In addition, the notion of previously administrated immunotherapies must always draw the attention of laboratory specialists to the possibility of Ab-induced interference in immunoassays. Ideally, an interfering therapy should automatically be flagged; thus, minimizing interference risk can also be achieved by connections between health information systems and laboratory information systems.

\section{CONCLUSION}

Immunoassays are inherently fragile but will remain in practice for many hormone measurements for years to come. This review outlines the importance of having excellent knowledge of the design and characteristics of laboratory immunoassays to appropriately suspect interference. Changes in medical practice and development of new therapies and sociological trends (such as biotin-loaded dietary supplements) might affect immunoassay-based diagnoses. New interferents will be identified; therefore, laboratory specialists should not ignore or underestimate immunoassay weaknesses and should establish a bi-directional, open, and permanent dialogue with clinicians to rapidly identify any suspected results before making further diagnostic or therapeutic decisions.

\section{ACKNOWLEDGEMENTS}

None.

\section{AUTHOR CONTRIBUTIONS}

Piketty $M$ and Ghazal K wrote the review. Brabant S and Prie D confirmed that they have significantly participated in revising the entire content and have approved the final submission of this review.

\section{CONFLICTS OF INTEREST}

The authors state no conflict of interest.

\section{RESEARCH FUNDING}

None.

\section{ORCID}

Khaldoun Ghazal https://orcid.org/0000-0002-3006-9274

Severine Brabant Dominique Prie https://orcid.org/0000-0002-7590-3963 https://orcid.org/0000-0003-3478-9778

Marie-Liesse Piketty https://orcid.org/0000-0002-9410-4796

\section{REFERENCES}

1. Wu AH. A selected history and future of immunoassay development and applications in clinical chemistry. Clin Chim Acta 2006;369:11924.

2. Sturgeon CM and Viljoen A. Analytical error and interference in immunoassay: minimizing risk. Ann Clin Biochem 2011;48:418-32.

3. Köhler $\mathrm{G}$ and Milstein C. Continuous cultures of fused cells secreting antibody of predefined specificity. Nature 1975;256:495-7.

4. Tate $J$ and Ward G. Interferences in immunoassay. Clin Biochem Rev 2004;25:105-20.

5. Sturgeon CM. External quality assessment of hormone determinations. 
Best Pract Res Clin Endocrinol Metab 2013;27:803-22.

6. Darwish IA. Immunoassay methods and their applications in pharmaceutical analysis: basic methodology and recent advances. Int J Biomed Sci 2006;2:217-35

7. Caruso B, Bovo C, Guidi GC. Causes of preanalytical interferences on laboratory immunoassays-A critical review. EJIFCC 2020;31:70-84.

8. Gnocchi D and Bruscalupi G. Circadian rhythms and hormonal homeostasis: pathophysiological implications. Biology (Basel) 2017;6:10.

9. Long N, Nguyen L, Stevermer J. PURLS: It's time to reconsider earlymorning testosterone tests. J Fam Pract 2015;64:418-9.

10. Selby C. Interference in immunoassay. Ann Clin Biochem 1999;36: 704-21.

11. Owen LJ, Monaghan PJ, Armstrong A, Keevil BG, Higham C, Salih Z, et al. Oestradiol measurement during fulvestrant treatment for breast cancer. Br J Cancer 2019;120:404-6.

12. Mandic S, Kratzsch J, Mandic D, Debeljak Z, Lukic I, Horvat V, et al. Falsely elevated serum oestradiol due to exemestane therapy. Ann Clin Biochem 2017;54:402-5.

13. Valdes R and Jortani SA. Unexpected suppression of immunoassay results by cross-reactivity: now a demonstrated cause for concern. Clin Chem 2002;48:405-6.

14. Lopez AG, Fraissinet F, Lefebvre H, Brunel V, Ziegler F. Pharmacological and analytical interference in hormone assays for diagnosis of adrenal incidentaloma. Ann Endocrinol (Paris) 2019;80:250-8.

15. Groenestege WM, Bui HN, ten Kate J, Menheere PP, Oosterhuis WP, Vader HL, et al. Accuracy of first and second generation testosterone assays and improvement through sample extraction. Clin Chem 2012; 58:1154-6.

16. Benton SC, Nuttall M, Nardo L, Laing I. Measured dehydroepiandrosterone sulfate positively influences testosterone measurement in unextracted female serum: comparison of 2 immunoassays with testosterone measured by LC-MS. Clin Chem 2011;57:1074-5.

17. Honour JW. Steroid assays in paediatric endocrinology. J Clin Res Pediatr Endocrinol 2010;2:1-16.

18. Paisley AN, Hayden K, Ellis A, Anderson J, Wieringa G, Trainer PJ. Pegvisomant interference in $\mathrm{GH}$ assays results in underestimation of GH levels. Eur J Endocrinol 2007;156:315-9.

19. Manolopoulou J, Alami Y, Petersenn S, Schopohl J, Wu Z, Strasburger $\mathrm{CJ}$, et al. Automated 22-kD growth hormone-specific assay without interference from Pegvisomant. Clin Chem 2012;58:1446-56.

20. Raff $\mathrm{H}$ and Findling JW. A new immunoradiometric assay for corticotropin evaluated in normal subjects and patients with Cushing's syndrome. Clin Chem 1989;35:596-600.

21. Woeber KA, White A, Kurtz TW. Recurrent pituitary macroadenoma with increased plasma ACTH precursors that cross-react in a commonly used ACTH immunoassay. Endocr Pract 2014;20:94-6.

22. Parfitt C, Church D, Armston A, Couchman L, Evans C, Wark G, et al. Commercial insulin immunoassays fail to detect commonly prescribed insulin analogues. Clin Biochem 2015;48:1354-7.

23. Dayaldasani A, Rodríguez Espinosa M, Ocón Sánchez P, Pérez Valero V. Cross-reactivity of insulin analogues with three insulin assays. Ann Clin Biochem 2015;52:312-8.

24. Giurgea I, Ulinski T, Touati G, Sempoux C, Mochel F, Brunelle F, et al. Factitious hyperinsulinism leading to pancreatectomy: severe forms of Munchausen syndrome by proxy. Pediatrics 2005;116:e145-8.

25. Drees JC, Stone JA, Reamer CR, Arboleda VE, Huang K, Hrynkow J, et al. Falsely undetectable TSH in a cohort of South Asian euthyroid patients. J Clin Endocrinol Metab 2014;99:1171-9.

26. Ward G, Simpson A, Boscato L, Hickman PE. The investigation of interferences in immunoassay. Clin Biochem 2017;50:1306-11.
27. Haddad RA, Giacherio D, Barkan AL. Interpretation of common endocrine laboratory tests: technical pitfalls, their mechanisms and practical considerations. Clin Diabetes Endocrinol 2019;5:12.

28. Frieze TW, Mong DP, Koops MK. "Hook effect" in prolactinomas: case report and review of literature. Endocr Pract 2002;8:296-303.

29. Bolstad N, Warren DJ, Nustad K. Heterophilic antibody interference in immunometric assays. Best Pract Res Clin Endocrinol Metab 2013; 27:647-61.

30. Ismail AA. Identifying and reducing potentially wrong immunoassay results even when plausible and "not-unreasonable". Adv Clin Chem 2014;66:241-94.

31. Favresse J, Burlacu MC, Maiter D, Gruson D. Interferences with thyroid function immunoassays: clinical implications and detection algorithm. Endocr Rev 2018;39:830-50.

32. Kricka LJ. Human anti-animal antibody interferences in immunological assays. Clin Chem 1999;45:942-56.

33. Bergman D, Larsson A, Hansson-Hamlin H, Åhlén E, Holst BS. Characterization of canine anti-mouse antibodies highlights that multiple strategies are needed to combat immunoassay interference. Sci Rep 2019:9:14521.

34. Boscato LM and Stuart MC. Heterophilic antibodies: a problem for al immunoassays. Clin Chem 1988;34:27-33.

35. Hattori N, Ishihara T, Shimatsu A. Variability in the detection of macro TSH in different immunoassay systems. Eur J Endocrinol 2016;174:915.

36. Giovanella $L$ and Ghelfo $A$. Undetectable serum thyroglobulin due to negative interference of heterophile antibodies in relapsing thyroid carcinoma. Clin Chem 2007;53:1871-2.

37. Ramaeker D, Brannian J, Egland K, McCaul K, Hansen K. When is elevated testosterone not testosterone? When it is an immunoassay interfering antibody. Fertil Steril 2008;90:886-8.

38. Brugts MP, Luermans JG, Lentjes EG, Van Trooyen-van Vrouwerff NJ, Van der Horst FA, Slee PH, et al. Heterophilic antibodies may be a cause of falsely low total IGF1 levels. Eur J Endocrinol 2009;161:561-5.

39. Saleem M, Lewis JG, Florkowski CM, Mulligan GP, George PM, Hale P. A patient with pseudo-Addison's disease and falsely elevated thyroxine due to interference in serum cortisol and free thyroxine immunoassays by two different mechanisms. Ann Clin Biochem 2009;46:172-5.

40. Gulbahar O, Konca Degertekin C, Akturk M, Yalcin MM, Kalan I, Atikeler GF, et al. A case with immunoassay interferences in the measurement of multiple hormones. J Clin Endocrinol Metab 2015;100:214753.

41. García-González E, Aramendía M, Álvarez-Ballano D, Trincado P, RelIo L. Serum sample containing endogenous antibodies interfering with multiple hormone immunoassays. Laboratory strategies to detect interference. Pract Lab Med 2015;4:1-10.

42. Oei AL, Sweep FC, Massuger LF, Olthaar AJ, Thomas CM. Transient human anti-mouse antibodies (HAMA) interference in CA 125 measurements during monitoring of ovarian cancer patients treated with murine monoclonal antibody. Gynecol Oncol 2008;109:199-202.

43. Kazmierczak SC, Catrou PG, Briley KP. Transient nature of interference effects from heterophile antibodies: examples of interference with cardiac marker measurements. Clin Chem Lab Med 2000;38:33-9.

44. Berglund Land Holmberg NG. Heterophilic antibodies against rabbit serum causing falsely elevated gonadotropin levels. Acta Obstet Gynecol Scand 1989;68:377-8.

45. Klee GG. Interferences in hormone immunoassays. Clin Lab Med 2004; 24:1-18

46. Ismail AA. On the diagnosis of subclinical hypothyroidism. Br J Gen Pract 2007;57:1000-1. 
47. Lu RM, Hwang YC, Liu IJ, Lee CC, Tsai HZ, Li HJ, et al. Development of therapeutic antibodies for the treatment of diseases. J Biomed Sci 2020;27:1.

48. Castinetti F, Albarel F, Archambeaud F, Bertherat J, Bouillet B, Buffier $P$, et al. French endocrine society guidance on endocrine side effects of immunotherapy. Endocr Relat Cancer 2019;26:G1-18.

49. Lahlou $\mathrm{N}$ and Raverot $\mathrm{V}$. Expert opinions on endocrine toxicity induced by new anticancer therapies: precautions to be taken in performing and interpreting hormonal assays under immunotherapy. Ann Endocrinol (Paris) 2018;79:550-4.

50. Koshida S, Asanuma K, Kuribayashi K, Goto M, Tsuji N, Kobayashi D, et al. Prevalence of human anti-mouse antibodies (HAMAs) in routine examinations. Clin Chim Acta 2010;411:391-4.

51. Emerson JF and Lai KKY. Endogenous antibody interferences in immunoassays. Lab Med 2013;44:69-73.

52. Jonklaas J. TSH-free thyroxine discordance in an athyreotic patient during ipiluminab and nivoluminab therapy. AACE Clin Case Rep 2016; 2:e296-301.

53. Kim D, Hong N, Cho Y, Lee SG, Rhee Y. Heterophile antibody interference associated with natural killer cell therapy. Endocr J 2020;67:118792.

54. Holm BE, Sandhu N, Tronstrøm J, Lydolph M, Trier NH, Houen G. Species cross-reactivity of rheumatoid factors and implications for immunoassays. Scand J Clin Lab Invest 2015;75:51-63.

55. Astarita G, Gutiérrez S, Kogovsek N, Mormandi E, Otero P, Calabrese C, et al. False positive in the measurement of thyroglobulin induced by rheumatoid factor. Clin Chim Acta 2015;447:43-6.

56. Mongolu S, Armston AE, Mozley E, Nasruddin A. Heterophilic antibody interference affecting multiple hormone assays: is it due to rheumatoid factor? Scand J Clin Lab Invest 2016;76:240-2.

57. Cheng X, Guo X, Chai X, Hu Y, Lian X, Zhang G. Heterophilic antibody interference with TSH measurement on different immunoassay platforms. Clin Chim Acta 2021;512:63-5.

58. Laudes M, Frohnert J, Ivanova K, Wandinger KP. PTH immunoassay interference due to human anti-mouse antibodies in a subject with obesity with normal parathyroid function. J Clin Endocrinol Metab 2019; 104:5840-2.

59. Fruzzetti F, Palla G, Sbrana A, Simoncini T, Sessa MR. Anti-goat antibodies as a rare cause of high gonadotropin levels during menopausal transition. Gynecol Endocrinol 2020;36:938-40.

60. Aliberti L, Gagliardi I, Dorizzi RM, Pizzicotti S, Bondanelli M, Zatelli MC, et al. Hypeprolactinemia: still an insidious diagnosis. Endocrine 2021; 72:928-31.

61. Hattori N, Aisaka K, Shimatsu A. A possible cause of the variable detectability of macroprolactin by different immunoassay systems. Clin Chem Lab Med 2016;54:603-8.

62. Overgaard M and Pedersen SM. Serum prolactin revisited: parametric reference intervals and cross platform evaluation of polyethylene glycol precipitation-based methods for discrimination between hyperprolactinemia and macroprolactinemia. Clin Chem Lab Med 2017;55: 1744-53.

63. Fahie-Wilson M and Smith TP. Determination of prolactin: the macroprolactin problem. Best Pract Res Clin Endocrinol Metab 2013;27:72542.

64. Hattori N, Ikekubo K, Nakaya Y, Kitagawa K, Inagaki C. Immunoglobulin $\mathrm{G}$ subclasses and prolactin (PRL) isoforms in macroprolactinemia due to anti-PRL autoantibodies. J Clin Endocrinol Metab 2005;90:303644.

65. Richa V, Rahul G, Sarika A. Macroprolactin; a frequent cause of misdiagnosed hyperprolactinemia in clinical practice. J Reprod Infertil
2010;11:161-7.

66. Fahie-Wilson M and Halsall D. Polyethylene glycol precipitation: proceed with care. Ann Clin Biochem 2008;45:233-5.

67. Barth JH, Lippiatt CM, Gibbons SG, Desborough RA. Observational studies on macroprolactin in a routine clinical laboratory. Clin Chem Lab Med 2018;56:1259-62.

68. Webster R, Fahie-Wilson M, Barker P, Chatterjee VK, Halsall DJ. Immunoglobulin interference in serum follicle-stimulating hormone assays: autoimmune and heterophilic antibody interference. Ann Clin Biochem 2010;47:386-9.

69. Ohba K, Maekawa M, Iwahara K, Suzuki Y, Matsushita A, Sasaki S, et al. Abnormal thyroid hormone response to TRH in a case of macroTSH and the cut-off value for screening cases of inappropriate TSH elevation. Endocr J 2020;67:125-30.

70. Loh TP, Kao SL, Halsall DJ, Toh SA, Chan E, Ho SC, et al. Macro-thyrotropin: a case report and review of literature. J Clin Endocrinol Metab 2012;97:1823-8.

71. Rix M, Laurberg P, Porzig C, Kristensen SR. Elevated thyroid-stimulating hormone level in a euthyroid neonate caused by macro thyrotropin-lgG complex. Acta Paediatr 2011;100:e135-7.

72. Halsall DJ, Fahie-Wilson MN, Hall SK, Barker P, Anderson J, Gama R, et al. Macro thyrotropin-IgG complex causes factitious increases in thyroid-stimulating hormone screening tests in a neonate and mother. Clin Chem 2006;52:1968-9; author reply 1969-70.

73. Haugen BR, Alexander EK, Bible KC, Doherty GM, Mandel SJ, Nikiforov YE, et al. 2015 American Thyroid Association management guidelines for adult patients with thyroid nodules and differentiated thyroid cancer: the American Thyroid Association guidelines task force on thyroid nodules and differentiated thyroid cancer. Thyroid 2016;26:1133.

74. Spencer C, LoPresti J, Fatemi S. How sensitive (second-generation) thyroglobulin measurement is changing paradigms for monitoring patients with differentiated thyroid cancer, in the absence or presence of thyroglobulin autoantibodies. Curr Opin Endocrinol Diabetes Obes 2014;21:394-404.

75. Giovanella L, Feldt-Rasmussen U, Verburg FA, Grebe SK, Plebani M, Clark PM. Thyroglobulin measurement by highly sensitive assays: focus on laboratory challenges. Clin Chem Lab Med 2015;53:1301-14.

76. Lupsa BC, Chong AY, Cochran EK, Soos MA, Semple RK, Gorden P. Autoimmune forms of hypoglycemia. Medicine (Baltimore) 2009;88: 141-53.

77. Ismail AA. The insulin autoimmune syndrome (IAS) as a cause of hypoglycaemia: an update on the pathophysiology, biochemical investigations and diagnosis. Clin Chem Lab Med 2016;54:1715-24.

78. Lamy PJ, Sault C, Renard E. High fasting serum insulin level due to autoantibody interference in insulin immunoassay discloses autoimmune insulin syndrome: a case report. Ann Biol Clin (Paris) 2016;74: 490-4.

79. Piketty ML, Brabant S, Souberbielle JC, Maruani G, Audrain C, Rothenbuhler A, et al. FGF23 measurement in burosumab-treated patients: an emerging treatment may induce a new analytical interference. Clin Chem Lab Med 2020;58:e267-9.

80. Lee MN, Lee SY, Hur KY, Park HD. Thyroxine (T4) autoantibody interference of free T4 concentration measurement in a patient with Hashimoto's thyroiditis. Ann Lab Med 2017;37:169-71.

81. Zouwail SA, O'Toole AM, Clark PM, Begley JP. Influence of thyroid hormone autoantibodies on 7 thyroid hormone assays. Clin Chem 2008; 54:927-8.

82. Massart C, Elbadii S, Gibassier J, Coignard V, Rasandratana A. Antithyroxine and anti-triiodothyronine antibody interferences in one-step 
free triiodothyronine and free thyroxine immunoassays. Clin Chim Acta 2009;401:175-6.

83. Beato-Víbora PI and Alejo-González S. Avoiding misdiagnosis due to antibody interference with serum free thyroxin. Int J Endocrinol Metab 2016;15:e37792.

84. Srichomkwun P, Scherberg NH, Jakšić J, Refetoff S. Diagnostic dilemma in discordant thyroid function tests due to thyroid hormone autoantibodies. AACE Clin Case Rep 2017;3:e22-5.

85. van der Watt G, Haarburger D, Berman P. Euthyroid patient with elevated serum free thyroxine. Clin Chem 2008;54:1239-41.

86. Colucci R, Lotti F, Arunachalam M, Lotti T, Dragoni F, Benvenga S, et al. Correlation of serum thyroid hormones autoantibodies with self-reported exposure to thyroid disruptors in a group of nonsegmental vitiligo patients. Arch Environ Contam Toxicol 2015;69:181-90.

87. Papo T, Oksenhendler E, Izembart M, Leger A, Clauvel JP. Antithyroid hormone antibodies induced by interferon-alpha. J Clin Endocrinol Metab 1992;75:1484-6.

88. Shimon I, Pariente C, Shlomo-David J, Grossman Z, Sack J. Transient elevation of triiodothyronine caused by triiodothyronine autoantibody associated with acute Epstein-Barr-virus infection. Thyroid 2003;13: 211-5.

89. Henry JG, Sobki S, Arafat N. Interference by biotin therapy on measurement of TSH and FT4 by enzyme immunoassay on Boehringer Mannheim ES700 analyser. Ann Clin Biochem 1996;33:162-3.

90. Trambas C. Biotin interference in clinical laboratory tests: sporadic problem or a serious clinical issue? In: Dasgupta A and Sepulveda JL, eds. Accurate results in the clinical laboratory. 2 nd ed. Amsterdam: Elsevier, 2019: 83-97.

91. Barbesino G. Misdiagnosis of Graves' disease with apparent severe hyperthyroidism in a patient taking biotin megadoses. Thyroid 2016; 26:860-3

92. Elston MS, Sehgal S, Du Toit S, Yarndley T, Conaglen JV. Factitious Graves' disease due to biotin immunoassay interference-A case and review of the literature. J Clin Endocrinol Metab 2016;101:3251-5.

93. U.S. Food and Drug Administration. UPDATE: the FDA warns that biotin may interfere with lab tests: FDA safety communication. https:// www.fda.gov/medical-devices/safety-communications/update-fda-warnsbiotin-may-interfere-lab-tests-fda-safety-communication (Updated on 5 Nov 2019).

94. Piketty ML, Polak M, Flechtner I, Gonzales-Briceño L, Souberbielle JC. False biochemical diagnosis of hyperthyroidism in streptavidin-biotin-based immunoassays: the problem of biotin intake and related interferences. Clin Chem Lab Med 2017;55:780-8.

95. Carter GD, Berry J, Cavalier E, Durazo-Arvizu R, Gunter E, Jones G, et al. Biotin supplementation causes erroneous elevations of results in some commercial serum 25-hydroxyvitamin D (250HD) assays. J Steroid Biochem Mol Biol 2020;200:105639.

96. Plasse RA, Olson SW, Yuan CM, Nee R. Biotin supplement interference with immunoassays for parathyroid hormone and 25-hydroxyvitamin $\mathrm{D}$ in a patient with metabolic bone disease on maintenance hemodialysis. Clin Kidney J 2020;13:710-2.

97. Stieglitz HM, Korpi-Steiner N, Katzman B, Mersereau JE, Styner M. Suspected testosterone-producing tumor in a patient taking biotin supplements. J Endocr Soc 2018;2:563-9.

98. Bizzarri C, Giannone GA, Gervasoni J, Benedetti S, Albanese F, Dello Strologo L, et al. Unusual presentation of a Denys-Drash syndrome girl with undisclosed assumption of biotin. J Clin Res Pediatr Endocrinol 2020 Aug 25. doi: 10.4274/jcrpe.galenos.2020.2020.0064. Online ahead of print

99. Meany DL, Jan De Beur SM, Bill MJ, Sokoll LJ. A case of renal osteo- dystrophy with unexpected serum intact parathyroid hormone concentrations. Clin Chem 2009;55:1737-9.

100. Koehler VF, Mann U, Nassour A, Mann WA. Fake news? Biotin interference in thyroid immunoassays. Clin Chim Acta 2018;484:320-2.

101. Ranaivosoa MK, Ganel S, Agin A, Romain S, Parent X, Reix N. Chronic kidney failure and biotin: A combination inducing unusual results in thyroid and parathyroid investigations, report of 2 cases. Nephrol Ther 2017; 13:553-8.

102. Feldt MM. Delayed diagnosis of congenital hypothyroidism in a child with trisomy 21 and biotinidase deficiency and successful use of levothyroxine sodium oral solution. Case Rep Endocrinol 2020;2020: 8883969.

103. John JJ, Cooley V, Lipner SR. Assessment of biotin supplementation among patients in an outpatient dermatology clinic. J Am Acad Dermatol 2019;81:620-1.

104. Lipner SR. Update on biotin therapy in dermatology: time for a change. J Drugs Dermatol 2020;19:1264-5.

105. Soleymani T, Lo Sicco K, Shapiro J. The infatuation with biotin supplementation: is there truth behind its rising popularity? A Comparative analysis of clinical efficacy versus social popularity. J Drugs Dermato 2017; 16:496-500.

106. Pharmacovigilance Risk Assessment Committee. PRAC recommendations on signals. European Medicines Agency. https://www.ema.europa.eu/en/documents/prac-recommendation/prac-recommendationssignals-adopted-14-17-january-2019-prac-meeting_en.pdf (Updated on 11 Feb 2019).

107. Katzman BM, Lueke AJ, Donato LJ, Jaffe AS, Baumann NA. Prevalence of biotin supplement usage in outpatients and plasma biotin concentrations in patients presenting to the emergency department. Clin Biochem 2018;60:11-6.

108. Trambas CM, Liu KC, Luu H, Louey W, Lynch C, Yen T, et al. Further assessment of the prevalence of biotin supplementation and its impact on risk. Clin Biochem 2019;65:64-5.

109. Ijpelaar A, Beijers A, van Daal H, van den Ouweland JMW. Prevalence of detectable biotin in the Netherlands in relation to risk on immunoassay interference. Clin Biochem 2020;83:78-80.

110. Sanders A, Gama R, Ashby H, Mohammed P. Biotin immunoassay interference: a UK-based prevalence study. Ann Clin Biochem 2021;58: 66-9.

111. Goldschmidt CH and Cohen JA. The rise and fall of high-dose biotin to treat progressive multiple sclerosis. Neurotherapeutics 2020;17: 968-70.

112. Motte J and Gold R. High-dose biotin in multiple sclerosis: the end of the road. Lancet Neurol 2020;19:965-6.

113. Cree BAC, Cutter G, Wolinsky JS, Freedman MS, Comi G, Giovannoni G, et al. Safety and efficacy of MD1003 (high-dose biotin) in patients with progressive multiple sclerosis (SPI2): a randomised, double-blind, placebo-controlled, phase 3 trial. Lancet Neurol 2020;19:988-97.

114. Wolf B. High doses of biotin can interfere with immunoassays that use biotin-strept(avidin) technologies: implications for individuals with biotin-responsive inherited metabolic disorders. Mol Genet Metab 2019; 127:321-4

115. Evans N, Yates J, Tobin J, McGill J, Huynh T. Immunoassay interference secondary to therapeutic high-dose biotin: A paediatric case report. J Paediatr Child Health 2018;54:572-5.

116. Bülow Pedersen I and Laurberg P. Biochemical hyperthyroidism in a newborn baby caused by assay interaction from biotin intake. Eur Thyroid J 2016;5:212-5

117. Lefèvre CR, Peltier L, Damaj L, Valaize J, Bendavid C, Moreau C. Immunoassay disruption by high-dose biotin therapy: fair warning for 
neonatal care physicians. Pediatr Neurol 2020;112:8-9.

118. Avery G. Biotin interference in immunoassay: a review for the laboratory scientist. Ann Clin Biochem 2019;56:424-30.

119. Kummer S, Hermsen D, Distelmaier F. Biotin treatment mimicking Graves' disease. N Engl J Med 2016;375:704-6.

120. Piketty ML, Prie D, Sedel F, Bernard D, Hercend C, Chanson P, et al. High-dose biotin therapy leading to false biochemical endocrine profiles: validation of a simple method to overcome biotin interference. Clin Chem Lab Med 2017;55:817-25.

121. Biscolla RPM, Chiamolera MI, Kanashiro I, Maciel RMB, Vieira JGH. A single $10 \mathrm{mg}$ oral dose of biotin interferes with thyroid function tests. Thyroid 2017;27:1099-100.

122. Zhang Y, Wang R, Dong Y, Huang G, Ji B, Wang Q. Assessment of biotin interference in thyroid function tests. Medicine (Baltimore) 2020; 99:e19232.

123. Grimsey P, Frey N, Bendig G, Zitzler J, Lorenz O, Kasapic D, et al. Population pharmacokinetics of exogenous biotin and the relationship between biotin serum levels and in vitro immunoassay interference. Int J Pharmacokinet 2017;2:247-56.

124. Peyro Saint Paul L, Debruyne D, Bernard D, Mock DM, Defer GL. Pharmacokinetics and pharmacodynamics of MD1003 (high-dose biotin) in the treatment of progressive multiple sclerosis. Expert Opin Drug Metab Toxicol 2016;12:327-44.

125. Bowen R, Benavides R, Colón-Franco JM, Katzman BM, Muthukumar A, Sadrzadeh $\mathrm{H}$, et al. Best practices in mitigating the risk of biotin interference with laboratory testing. Clin Biochem 2019;74:1-11.

126. Gifford JL, de Koning L, Sadrzadeh SMH. Strategies for mitigating risk posed by biotin interference on clinical immunoassays. Clin Biochem 2019;65:61-3.

127. Mzougui S, Favresse J, Soleimani R, Fillée C, Gruson D. Biotin interference: evaluation of a new generation of electrochemiluminescent immunoassays for high-sensitive troponin $\mathrm{T}$ and thyroid-stimulating hormone testing. Clin Chem Lab Med 2020;58:2037-45.

128. Lam $L$ and Kyle CV. A simple method to detect biotin interference on immunoassays. Clin Chem Lab Med 2017;55:e104-6.

129. Trambas C, Lu Z, Yen T, Sikaris K. Depletion of biotin using streptavidin-coated microparticles: a validated solution to the problem of biotin interference in streptavidin-biotin immunoassays. Ann Clin Biochem 2018;55:216-26.

130. Moerman A and Delanghe JR. Sense and nonsense concerning biotin interference in laboratory tests. Acta Clin Belg 2020:1-7.

131. Rulander NJ, Cardamone D, Senior M, Snyder PJ, Master SR. Interference from anti-streptavidin antibody. Arch Pathol Lab Med 2013; 137:1141-6.

132. Verougstraete N, Berth M, Vaneechoutte M, Delanghe J, Callewaert N. Interference of anti-streptavidin antibodies in immunoassays: A very rare phenomenon or a more common finding? Clin Chem Lab Med 2020;58:1673-80.

133. Dahll LK, Haave EM, Dahl SR, Aas FE, Thorsby PM. Endogenous antistreptavidin antibodies causing erroneous laboratory results more common than anticipated. Scand J Clin Lab Invest 2021;81:92-103.

134. Berth M, Willaert S, De Ridder C. Anti-streptavidin IgG antibody interference in anti-cyclic citrullinated peptide (CCP) IgG antibody assays is a rare but important cause of false-positive anti-CCP results. Clin Chem Lab Med 2018;56:1263-8.

135. Raverot V, Bordeau É, Periot C, Perrin P, Chardon L, Plotton I, et al. Letter to the editor: A case of laboratory-generated "thyroid dysfunction". Ann Endocrinol (Paris) 2019;80:140-1.

136. Lam L, Bagg W, Smith G, Chiu WW, Middleditch MJ, Lim JC, et al. Apparent hyperthyroidism caused by biotin-like interference from IgM anti-streptavidin antibodies. Thyroid 2018;28:1063-7.

137. Peltier L, Massart C, Moineau MP, Delhostal A, Roudaut N. Anti-streptavidin interferences in Roche thyroid immunoassays: a case report. Clin Chem Lab Med 2016;54:e11-4.

138. Bayart JL, Favresse J, Melnik E, Lardinois B, Fillée C, Maiter D, et al. Erroneous thyroid and steroid hormones profile due to anti-streptavidin antibodies. Clin Chem Lab Med 2019;57:e255-8.

139. Heijboer AC, ljzerman RG, Bouman AA, Blankenstein MA. Two cases of antiruthenium antibody interference in Modular free thyroxine assay. Ann Clin Biochem 2009;46:263-4.

140. Buijs MM, Gorgels JP, Endert E. Interference by antiruthenium antibodies in the Roche thyroid-stimulating hormone assay. Ann Clin Biochem 2011;48:276-81.

141. Ando T, Yasui J, Inokuchi N, Usa T, Ashizawa K, Kamihara S, et al. Non-specific activities against ruthenium crosslinker as a new cause of assay interference in an electrochemilluminescent immunoassay. Intern Med 2007;46:1225-9.

142. Ohba K, Noh JY, Unno T, Satoh T, Iwahara K, Matsushita A, et al. Falsely elevated thyroid hormone levels caused by anti-ruthenium interference in the Elecsys assay resembling the syndrome of inappropriate secretion of thyrotropin. Endocr J 2012;59:663-7.

143. Zaninotto M, Tognon C, Venturini R, Betterle C, Plebani M. Interference in thyroid hormones with Roche immunoassays: an unfinished story. Clin Chem Lab Med 2014;52:e269-70.

144. Lim YY, Ong L, Loh TP, Sethi SK, Sng AAJ, Loke KY, et al. A diagnostic curiosity of isolated androstenedione elevation due to autoantibodies against horseradish peroxidase label of the immunoassay. Clin Chim Acta 2018;476:103-6.

145. Maharjan AS, Wyness SP, Ray JA, Willcox TL, Seiter JD, Genzen JR. Detection and characterization of estradiol (E2) and unconjugated estriol (UE3) immunoassay interference due to anti-bovine alkaline phosphatase (ALP) antibodies. Pract Lab Med 2019;17:e00131.

146. Sofronescu AG, Ross M, Rush E, Goldner W. Spurious testosterone laboratory results in a patient taking synthetic alkaline phosphatase (asfotase alfa). Clin Biochem 2018;58:118-21.

147. U.S. Food and Drug Administration medical devices databases. Class 2 device recall ST AIAPACK ACTH (ACTH). https://www.accessdata. fda.gov/scripts/cdrh/cfdocs/cfRes/res.cfm?ID=169038 (updated on 14 Jan 2021).

148. Altawallbeh $\mathrm{G}$ and Karger $\mathrm{AB}$. Letter to the Editor: assay-specific spurious $\mathrm{ACTH}$ results lead to misdiagnosis, unnecessary testing, and surgical misadventure-A case series. J Endocr Soc 2019;4:bvz011.

149. Luzzi VI, Scott MG, Gronowski AM. Negative thyrotropin assay interference associated with an IgGkappa paraprotein. Clin Chem 2003; 49:709-10.

150. Imperiali M, Jelmini P, Ferraro B, Keller F, della Bruna R, Balerna M, et al. Interference in thyroid-stimulating hormone determination. Eur J Clin Invest 2010;40:756-8.

151. Covinsky M, Laterza O, Pfeifer JD, Farkas-Szallasi T, Scott MG. An IgM lambda antibody to Escherichia coli produces false-positive results in multiple immunometric assays. Clin Chem 2000;46:1157-61.

152. Whittle E, de Waal E, Huynh T, Treacy O, Morton A. Pre-analytical mysteries: A case of severe hypervitaminosis D and mild hypercalcaemia. Biochem Med (Zagreb) 2021;31:011001.

153. Ismail AA. Interference from endogenous antibodies in automated immunoassays: what laboratorians need to know. J Clin Pathol 2009;62: 673-8.

154. Hager HB, Bolstad N, Warren DJ, Ness MV, Seierstad B, Lindberg M. Falsely markedly elevated 25 -hydroxyvitamin $\mathrm{D}$ in patients with monoclonal gammopathies. Clin Chem Lab Med 2021;59:663-9. 
155. Ong MW, Salota R, Reeman T, Lapsley M, Jones L. Artefactual 25-OH vitamin D concentration in multiple myeloma. Ann Clin Biochem 2017; 54:716-20.

156. Visser WE and Peeters RP. Interpretation of thyroid function tests during pregnancy. Best Pract Res Clin Endocrinol Metab 2020;34:101431.

157. Khoo S, Lyons G, McGowan A, Gurnell M, Oddy S, Visser WE, et al. Familial dysalbuminaemic hyperthyroxinaemia interferes with current free thyroid hormone immunoassay methods. Eur J Endocrinol 2020; 182:533-8.

158. Cartwright D, O'Shea P, Rajanayagam O, Agostini M, Barker P, Moran C, et al. Familial dysalbuminemic hyperthyroxinemia: A persistent diagnostic challenge. Clin Chem 2009;55:1044-6.

159. Ross HA, de Rijke YB, Sweep FC. Spuriously high free thyroxine values in familial dysalbuminemic hyperthyroxinemia. Clin Chem 2011; 57:524-5.

160. Kragh-Hansen U, Galliano M, Minchiotti L. Clinical, genetic, and protein structural aspects of familial dysalbuminemic hyperthyroxinemia and hypertriiodothyroninemia. Front Endocrinol (Lausanne) 2017;8: 297.

161. DeCosimo DR, Fang SL, Braverman LE. Prevalence of familial dysalbuminemic hyperthyroxinemia in Hispanics. Ann Intern Med 1987; 107:780-1.

162. Pappa T, Ferrara AM, Refetoff S. Inherited defects of thyroxine-binding proteins. Best Pract Res Clin Endocrinol Metab 2015;29:735-47.

163. Campi I, Covelli D, Moran C, Fugazzola L, Cacciatore C, Orlandi F, et al. The differential diagnosis of discrepant thyroid function tests: insistent pitfalls and updated flow-chart based on a long-standing experience. Front Endocrinol (Lausanne) 2020;11:432.

164. Dieu X, Bouzamondo N, Briet C, Illouz F, Moal V, Boux de Casson F, et al. Familial dysalbuminemic hyperthyroxinemia: an underdiagnosed entity. J Clin Med 2020;9:2105.

165. Rosner W, Auchus RJ, Azziz R, Sluss PM, Raff H. Position statement: utility, limitations, and pitfalls in measuring testosterone: an Endocrine Society position statement. J Clin Endocrinol Metab 2007;92:405-13.

166. Keevil BG and Adaway J. Assessment of free testosterone concentration. J Steroid Biochem Mol Biol 2019;190:207-11.

167. Faye SA, Groome N, Masica R, Kertez G. Investigation and resolution of the effect of an interfering factor in the Beckman Coulter anti-Müllerian hormone (AMH) Gen II ELISA assay. Hum Reprod 2014;29:331.

168. Turner KA, Larson BJ, Kreofsky NC, Willrich MAV, Bornhorst JA, Algeciras-Schimnich $\mathrm{A}$. Assessment of complement interference in antiMüllerian hormone immunoassays. Clin Chem Lab Med 2020;58:e810.

169. Monaghan PJ, Kyriacou A, Sturgeon C, Davies A, Trainer PJ, White A, et al. Proopiomelanocortin interference in the measurement of adrenocorticotrophic hormone: a United Kingdom National External Quality Assessment Service study. Clin Endocrinol (Oxf) 2016;85:569-74.

170. Lauro C, Corcuff J-B, Brossaud J, Georges A. What to do in the event of a suspicion of analytical interference during an immunoassay? Ann Biol Clin (Paris) 2020;78:70-3.

171. Gurnell M, Halsall DJ, Chatterjee VK. What should be done when thyroid function tests do not make sense? Clin Endocrinol (Oxf) 2011;74: 673-8.

172. Cavalier E, Carlisi A, Chapelle JP, Delanaye P. False positive PTH results: an easy strategy to test and detect analytical interferences in routine practice. Clin Chim Acta 2008;387:150-2.

173. Ellis MJ and Livesey JH. Techniques for identifying heterophile antibody interference are assay specific: study of seven analytes on two automated immunoassay analyzers. Clin Chem 2005;51:639-41.

174. Choy KW, Teng J, Wijeratne N, Tan CY, Doery JC. Immunoassay inter- ference complicating management of Cushing's disease: the onus is on the clinician and the laboratory. Ann Clin Biochem 2017;54:183-4.

175. Faix JD. Principles and pitfalls of free hormone measurements. Best Pract Res Clin Endocrinol Metab 2013;27:631-45.

176. Ismail AA. On detecting interference from endogenous antibodies in immunoassays by doubling dilutions test. Clin Chem Lab Med 2007; 45:851-4.

177. Cole LA and Khanlian SA. Easy fix for clinical laboratories for the falsepositive defect with the Abbott AxSym total $\beta$-hCG test. Clin Biochem 2004;37:344-9.

178. Santhana Krishnan SG, Pathalapati R, Kaplan L, Cobbs RK. Falsely raised TSH levels due to human anti-mouse antibody interfering with thyrotropin assay. Postgrad Med J 2006;82:e27.

179. Interlaboratory survey of methods for measuring human anti-mouse antibodies. HAMA Survey Group. Clin Chem 1992;38:172-3.

180. Favresse J, Lardinois B, Nassogne MC, Preumont V, Maiter D, Gruson D. Anti-streptavidin antibodies mimicking heterophilic antibodies in thyroid function tests. Clin Chem Lab Med 2018;56:e160-3.

181. Giovanella L, Giordani I, Imperiali M, Orlandi F, Trimboli P. Measuring procalcitonin to overcome heterophilic-antibody-induced spurious hypercalcitoninemia. Clin Chem Lab Med 2018;56:e191-3.

182. Wong T, Shackleton CH, Covey TR, Ellis G. Identification of the steroids in neonatal plasma that interfere with 17 alpha-hydroxyprogesterone radioimmunoassays. Clin Chem 1992;38:1830-7.

183. Makela SK and Ellis G. Nonspecificity of a direct 17 alpha-hydroxyprogesterone radioimmunoassay kit when used with samples from neonates. Clin Chem 1988;34:2070-5.

184. Hawley JM, Owen LJ, Lockhart SJ, Monaghan PJ, Armston A, Chadwick CA, et al. Serum cortisol: an up-to-date assessment of routine assay performance. Clin Chem 2016;62:1220-9.

185. Vogeser M, Kratzsch J, Ju Bae Y, Bruegel M, Ceglarek U, Fiers T, et al. Multicenter performance evaluation of a second generation cortisol assay. Clin Chem Lab Med 2017;55:826-35.

186. Thomas CM, van den Berg RJ, Segers MF, Bartelink ML, Thien T. Inaccurate measurement of 17 beta-estradiol in serum of female volunteers after oral administration of milligram amounts of micronized 17 beta-estradiol. Clin Chem 1993;39:2341-2.

187. Nahoul K, Dehennin L, Scholler R. Radioimmunoassay of plasma progesterone after oral administration of micronized progesterone. J Steroid Biochem 1987;26:241-9.

188. Taieb J, Mathian B, Millot F, Patricot MC, Mathieu E, Queyrel N, et al. Testosterone measured by 10 immunoassays and by isotope-dilution gas chromatography-mass spectrometry in sera from 116 men, women, and children. Clin Chem 2003;49:1381-95.

189. Warner MH, Kane JW, Atkin SL, Kilpatrick ES. Dehydroepiandrosterone sulphate interferes with the Abbott Architect direct immunoassay for testosterone. Ann Clin Biochem 2006;43:196-9.

190. Piketty ML, d'Herbomez M, Le Guillouzic D, Lebtahi R, Cosson E, Dumont A, et al. Clinical comparison of three labeled-antibody immunoassays of free triiodothyronine. Clin Chem 1996;42:933-41.

191. Krasowski MD, Drees D, Morris CS, Maakestad J, Blau JL, Ekins S. Cross-reactivity of steroid hormone immunoassays: clinical significance and two-dimensional molecular similarity prediction. BMC Clin Pathol 2014; 14:33.

192. Dias ML, Vieira JG, Abucham J. Detecting and solving the interference of pregnancy serum, in a GH immunometric assay. Growth Horm IGF Res 2013;23:13-8.

193. Schiettecatte J, Strasser O, Anckaert E, Smitz J. Performance evaluation of an automated electrochemiluminescent calcitonin (CT) immunoassay in diagnosis of medullary thyroid carcinoma. Clin Biochem 
Ghazal K, et al.

Hormone immunoassay interference
ANNALS OF

LABORATORY MEDICINE
2016;49:929-31.

194. Hillebrand JJ, Siegelaar SE, Heijboer AC. Falsely decreased thyroglobulin levels in a patient with differentiated thyroid carcinoma. Clin Chim Acta 2020;509:217-9.

195. Cormano J, Mackay G, Holschneider C. Gestational trophoblastic dis- ease diagnosis delayed by the hook effect. Obstet Gynecol 2015;126: 811-4.

196. Pillay TS, Muyldermans S. Application of single domain antibodies ("nanobodies") to laboratory diagnosis. Ann Lab Med 2021;41:54958. 